\title{
Qualitative Description of College Students' Dinner Groups
}

Brita Michelle Ball

Brigham Young University - Provo

Follow this and additional works at: https://scholarsarchive.byu.edu/etd

Part of the Food Science Commons, and the Nutrition Commons

\section{BYU ScholarsArchive Citation}

Ball, Brita Michelle, "Qualitative Description of College Students' Dinner Groups" (2010). Theses and Dissertations. 2516.

https://scholarsarchive.byu.edu/etd/2516

This Thesis is brought to you for free and open access by BYU ScholarsArchive. It has been accepted for inclusion in Theses and Dissertations by an authorized administrator of BYU ScholarsArchive. For more information, please contact scholarsarchive@byu.edu, ellen_amatangelo@byu.edu. 
Qualitative Description of College Students' Dinner Groups

Brita Michelle Ball

A thesis submitted to the faculty of

Brigham Young University

in partial fulfillment of the requirements for the degree of

Master of Science

Lora Beth Brown, Chair

Rickelle Richards

Nora Nyland

Department of Nutrition, Dietetics, and Food Science

Brigham Young University

August 2010

Copyright (C) 2010 Brita Ball

All Rights Reserved 


\author{
ABSTRACT \\ Qualitative Description of College Students' Dinner Groups \\ Brita Michelle Ball \\ Department of Nutrition, Dietetics, and Food Science \\ Master of Science
}

Objective: The purpose of this study was to discover how college students conduct dinner groups and students' perceptions of the benefits and difficulties of participation.

Design: Qualitative study conducted with seven focus groups.

Setting: A university campus.

Participants: Thirty-six college students participating in dinner groups. Dinner groups were defined as a group of $\geq 3$ people cooking for each other (or together) and eating together $\geq 4$ times a week.

Analysis: The focus groups were recorded, transcribed, coded, and reconciled. NUDIST ${ }^{\circledR}$ NVivo software was used in identifying themes and subthemes.

Results: Dinner groups were composed of roommates and/or other students living nearby. They rotated who made each dinner. Benefits identified included social interaction, increasing confidence in cooking, saving money and time, and eating more varied and healthier foods. Difficulties were mentioned but were much less common. They included increased time spent on days the student cooked and stresses related to cooking on a schedule. Students found that the benefits far outweighed the difficulties and universally wanted to continue in a dinner group.

Conclusions and Implications: College students enjoy dinner groups and promoting them may be an option for improving college students' eating habits. Nearly all students felt that they ate better in a dinner group but research is needed to assess actual intake.

KEY WORDS: nutrition, dinner groups, young adults, focus groups 


\section{ACKNOWLEDGMENTS}

I would like to acknowledge and thank my advisor Dr. Lora Beth Brown for her guidance, support, and assistance throughout the research and writing of this thesis. My committee members Dr. Rickelle Richards and Dr. Nora Nyland also provided helpful advice and direction. Dr. Eggett and Dr. Franz were important and inspiring teachers who helped me gain a passion for research and nutrition.

Many thanks to my fellow graduate students who were experiencing the journey with me.

They were instrumental in getting me through those times where I was burnt out or frustrated and celebrating with me during my accomplishments. Jessica Zetterquist and Tianna Watson were especially helpful with orals, course work, research and by just being someone to talk to.

I am also grateful to those students who were willing to participate in my study and excited about dinner groups.

Lastly, I appreciate all the encouragement and support that has been provide by my friends and family. They have believed in me and were there from the beginning to the end when the final touches were put into place. 


\section{TABLE OF CONTENTS}

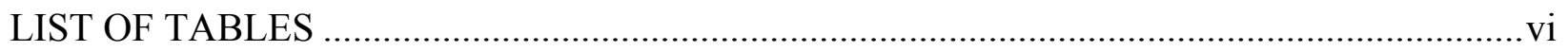

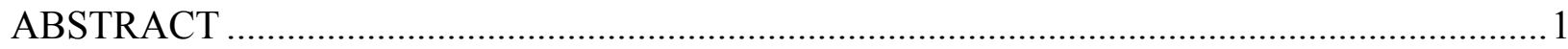

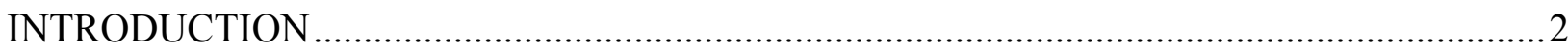

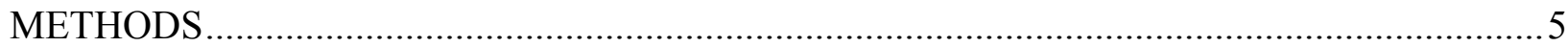

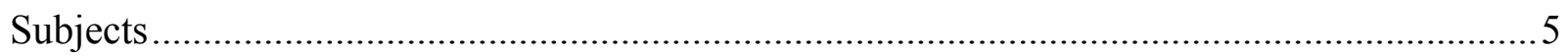

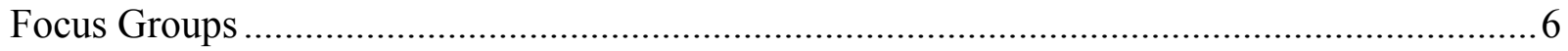

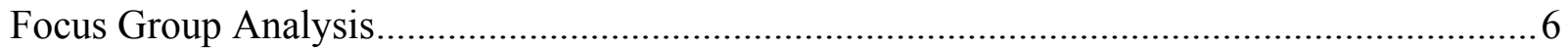

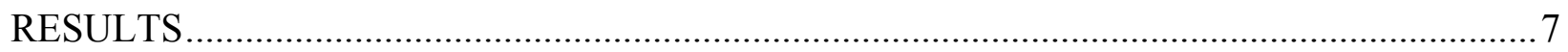

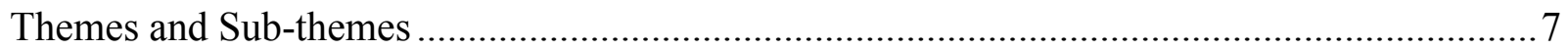

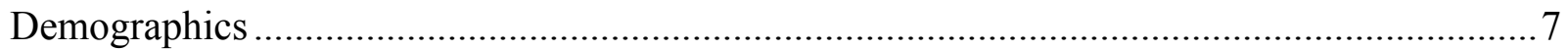

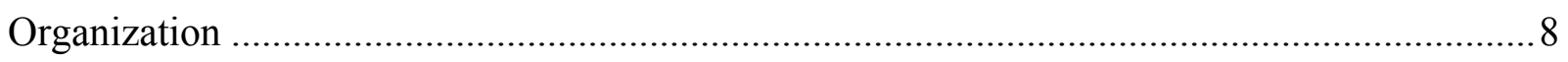

Environmental, Behavioral, and Personal Benefits …………………………......................10

Environmental, Behavioral, and Personal Difficulties ...........................................................15

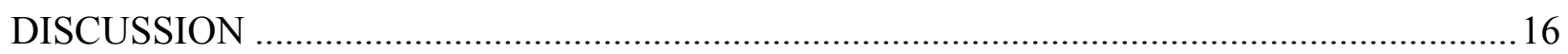

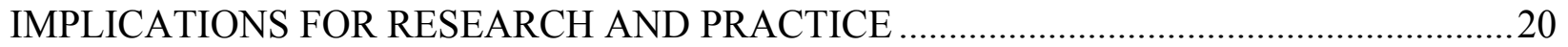

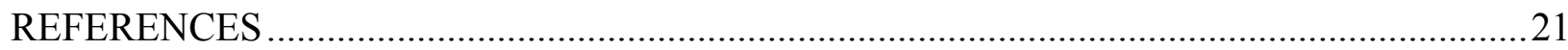

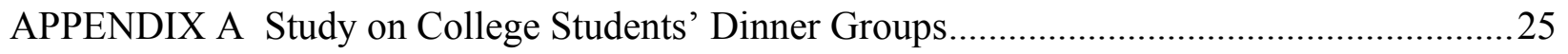

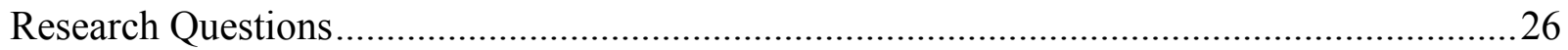

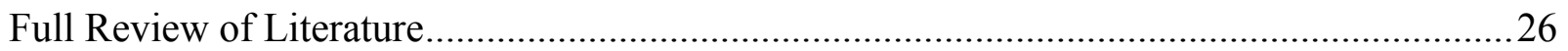

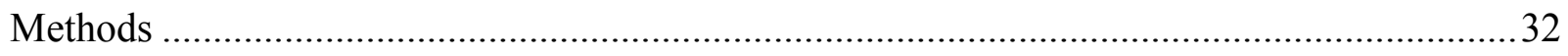

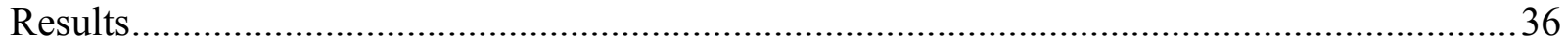

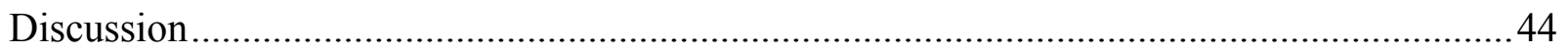

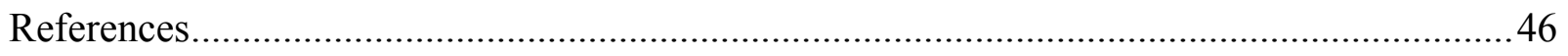

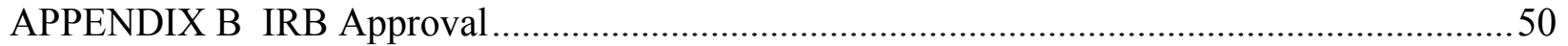

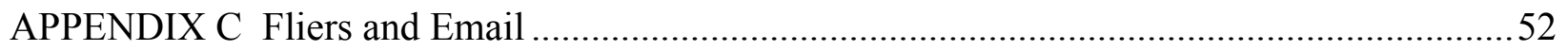

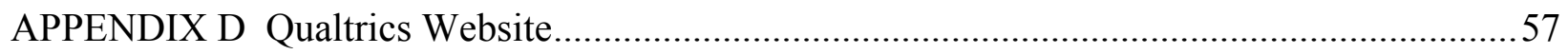

APPENDIX E Focus Group Consent and Questionnaire ..........................................................62

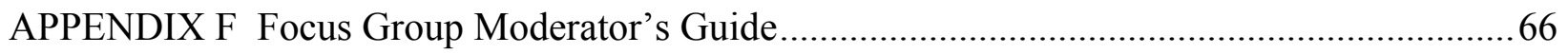




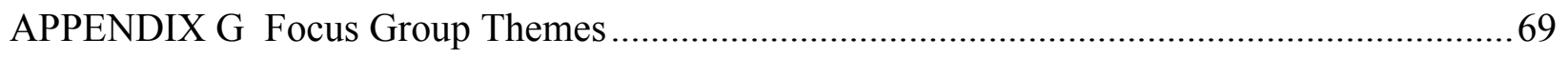

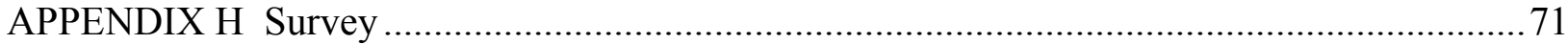




\section{LIST OF TABLES}

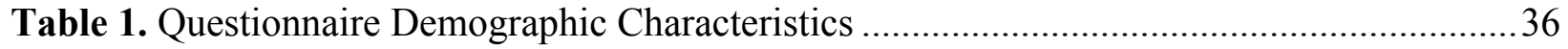

Table 2. Questionnaire Dinner Group Characteristics.................................................... 36

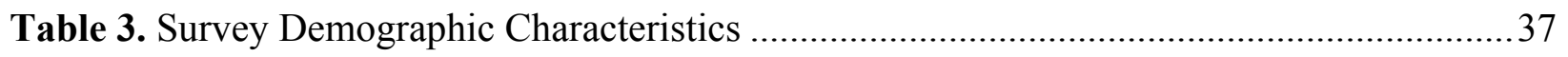

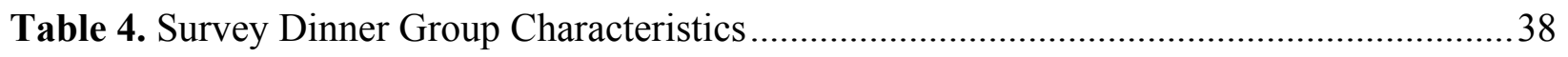

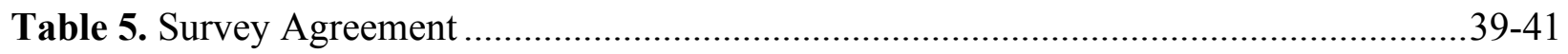

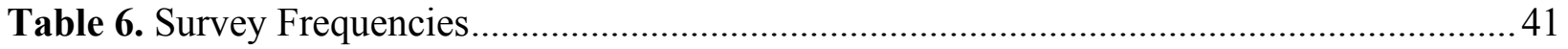




\begin{abstract}
Qualitative Description of College Students’ Dinner Groups

Brita Ball, MS

Lora Beth Brown, EdD, RD
\end{abstract}

Objective: The purpose of this study was to discover how college students conduct dinner groups and students' perceptions of the benefits and difficulties of participation.

Design: Qualitative study conducted with seven focus groups.

Setting: A university campus.

Participants: Thirty-six college students participating in dinner groups. Dinner groups were defined as a group of $\geq 3$ people cooking for each other (or together) and eating together $\geq 4$ times a week.

Analysis: The focus groups were recorded, transcribed, coded, and reconciled. NUDIST $®$ NVivo software was used in identifying themes and subthemes.

Results: Dinner groups were composed of roommates and/or other students living nearby. They rotated who made each dinner. Benefits identified included social interaction, increasing confidence in cooking, saving money and time, and eating more varied and healthier foods. Difficulties were mentioned but were much less common. They included increased time spent on days the student cooked and stresses related to cooking on a schedule. Students found that the benefits far outweighed the difficulties and universally wanted to continue in a dinner group.

Conclusions and Implications: College students enjoy dinner groups and promoting them may be an option for improving college students' eating habits. Nearly all students felt that they ate better in a dinner group but research is needed to assess actual intake.

Department of Nutrition, Food Science and Dietetics, Brigham Young University, Provo, Utah.

KEY WORDS: dinner groups, young adults, focus groups 


\section{INTRODUCTION}

Studies of young adults and their eating habits are limited in number and scope. Data suggest that a majority of young adults consume diets that are excessive in fat and inadequate in

servings of calcium-rich foods, fruits, deep yellow and green vegetables and whole grains. ${ }^{1,2}$ One study found that less than $50 \%$ of young adult females are meeting the recommendations for vitamin D, folate, calcium, potassium, and iron. Males overall are closer than females to meeting the recommendations but still eat only about $50 \%$ of the recommendation for vitamin $\mathrm{D}$, folate, calcium, and potassium. ${ }^{3}$ This study also found that young adults have high rates of overweight and are at high risk of chronic disease, based on high blood pressure values and LDL (lowdensity lipoprotein) cholesterol levels. ${ }^{3}$ Another study found that college students self-reported that they thought they ate too much sugar and processed carbohydrate and too much fat, saturated fat and trans fat. ${ }^{4}$ Those who attend a 4-year college eat more frequent meals and have a better intake than do those at a 2-year college or nonstudents. This may be because nonstudents and 2-year college students have a higher proportion of minorities and lower socioeconomic status. ${ }^{5}$

Anecdotal comments show that young adults used to cook and eat together while attending school away from home, but documentation of this practice has not been found in the published literature. The current extent of such communal cooking and eating is also unknown, and students' social eating habits when living on their own are largely undocumented. One study reported that the majority of students participants eat dinner with other people, ${ }^{6}$ but who those 
dinner partners are was not reported and almost half of the young adults studied lived at home, while only $13 \%$ lived on campus. ${ }^{2}$ Half of the males and slightly over half of females also said that they tend to eat on the run, ${ }^{6}$ which may mean they are eating alone.

Many barriers to nutritious eating in young adults have been identified. Barriers to preparing meals include time available to prepare meals, inadequate cooking skills, and not having enough money to buy food. ${ }^{2}$ College students' food preparation knowledge is low and they tend to overestimate their knowledge. ${ }^{7}$ Children today are less likely to learn cooking skills in school before leaving home, ${ }^{8}$ and young adults who lack cooking skills are prone to eat away from home or eat premade meals. ${ }^{9}$

The top factors affecting students' food choices are convenience, taste, and cost. ${ }^{10}$ This is exemplified in another study showing that, as young female adults increase their hours of employment, the frequency of fast food consumption also increases. ${ }^{11}$ Of adult respondents (16 and older), 92\% chose "fast" as a reason for choosing fast food. ${ }^{12}$ This study of adults also found that young adults were more likely than other adults to report eating out to socialize, which is consistent with other findings in young adults that eating with family and friends was a reason for eating out. ${ }^{4}$ Almost half of the students in one young adult study ate at fast food locations at least weekly. ${ }^{13}$ Food that is eaten out typically contains more total calories as well as more saturated and total fat than food eaten at home. ${ }^{14}$ In one study of college students, socializing with friends was the reason most commonly chosen for eating out. ${ }^{13}$

One type of social eating that has been studied widely is family meals. When families eat together they may be more likely to prepare well-balanced, nutritious meals, while adolescents eating on their own may rely more on prepackaged convenience foods. ${ }^{15}$ Family meals may provide an opportunity for parents to provide an example of healthy eating and offer healthful 
food choices. ${ }^{1,16}$ Interactions about food with family members transmit food attitudes, preferences, and values. ${ }^{17}$ Family meals are significantly associated with greater intakes of healthy foods and important nutrients during adolescence and young adulthood. ${ }^{1,15}$ Having more frequent family meals in adolescence predicts an increased meal structure and higher priority for social eating in young adulthood. ${ }^{1}$ The Satter eating competence model (ecSatter) approaches good nutrition through focus on the whole eating experience. Eating competence as defined in ecSatter has structure and forethought, internal regulation of food intake, a positive approach toward a variety of foods, and a positive attitude about eating in general. ${ }^{18}$ This approach to eating starts with factors that are easily part of family meals and could potentially be part of other types of social eating.

The current study describes a specific type of social eating among college students. Young adult dinner groups are a phenomenon that researchers have not found described in the literature. For this study, dinner groups were defined as three or more people cooking for each other (or together) and eating together least four times a week. The purpose of this study was to identify the different ways that dinner groups are planned, organized, and implemented, as well as students' perceptions of benefits and difficulties related to participation in dinner groups. Constructs from the Social Cognitive Theory (SCT) were used in organizing and interpreting the results of this study. The SCT constructs used include behavioral capabilities, observational learning, expectations (outcomes), expectancies (value placed on the outcomes), and selfefficacy. ${ }^{19,20}$ The concept of reciprocal determinism was incorporated. This concept explains that behavior is described as not simply the result of the environment and the person, but is both influenced by them and influences them in return. ${ }^{19}$ Environmental factors include a person's surroundings such as facilities, food availability, and other people. Behavioral factors include 
knowledge and skills related to cooking, while personal factors include belief that they can perform a task (self-efficacy) and that a behavior will result in benefits that they value (expectations and expectancies). ${ }^{20}$

\section{METHODS}

\section{Subjects}

Approval was obtained from the university's institutional review board for human subjects, and data were collected from students at Brigham Young University (BYU) during the spring of 2009. The study population included thirty-six students, eight males and twenty-eight females, who participated in seven focus groups. The mean age of participants was 21.6 years (range 19 to 26). The BYU campus was used because it was known that some students attending this university participate in dinner groups.

The participants were recruited through fliers placed at apartment complexes and in BYU campus buildings. Announcements were also made in general education classes at BYU and Utah Valley University (UVU), since some students from both universities share apartments. Although announcements were made in some UVU classes, no students from UVU participated in the study. Interested students who were currently participating in dinner groups were directed to an online website (Qualtrics) where they took a survey to determine if they were eligible to participate in the focus groups. Students were only included if they participated in a dinner group with three or more people cooking for each other (or together) and eating together at least four 
times a week. This definition was decided upon so that most of the dinner meals for a student would be coming from the dinner group and students who just ate with a significant other were not included. An incentive of ten dollars was offered to students for participation in the focus groups.

\section{Focus Groups}

Focus groups were held on the BYU campus at various times of day to try to accommodate as many students as possible. At each session the participants were identified by first name only for confidentiality. Each group was run by a moderator (BB) using the moderator's guide, which contained an introduction and preplanned questions. The questions were open-ended, and related to basic dinner group practices and the benefits and difficulties encountered by the participants. An assistant moderator (LBB) was present to take notes during the discussion. Discussions were tape-recorded and transcribed verbatim for analysis. At the beginning of the session, all participants completed a short questionnaire of demographic and basic dinner-group information. Each focus group was between sixty and ninety minutes long including the time allotted for completing the questionnaires. After each focus group was concluded, notes about students' responses were reviewed.

\section{Focus Group Analysis}

After the focus group recordings were transcribed, they were coded for major themes and sub-themes by two researchers. Each quote was given tags for the themes they included. The 
researchers then met together to reconcile differences in coding. As coding continued, new themes were occasionally added based on new topics discussed in the transcripts, and the primary researcher then reviewed earlier transcripts to make sure similar comments on those topics had not been previously overlooked. NUDIST NVivo (v. 8, 2008, Melbourne, Australia) was used to electronically code and sort participants' responses for managing data and preparing manuscripts. The comments were then analyzed to identify frequently-mentioned topics within the different themes.

\section{RESULTS}

\section{Themes and Sub-themes}

Comments were categorized and labeled with themes including organization, cooking, cooking for one, recipes, social, money, variety and health and saving time. There were also general positive comments, and general negative comments.

\section{Demographics}

The twenty-eight focus group participants ranged from freshmen to graduate students, most being sophomores, juniors and seniors. Students were enrolled in a mean of 14.3 credits (range 9 to 18), with most of the lower credit numbers from the 5 graduate students. Twenty- 
three of the students were employed and thirteen were unemployed. The mean length of participation in a dinner group was six semesters (range 1 to 11 semesters).

\section{Organization}

Many of the groups were initially organized by someone who asked others if they would like to join a dinner group. The informal organizer then created one or more groups based on the number of people who signed up. The number of people in the dinner groups ranged from 3 to 30. Participants rotated to the apartment of the person who was cooking, except in the dinner groups composed only of roommates. There were five focus group participants, all females, who were in dinner groups that consisted only of roommates. Most participants reported that they cooked individually for their group but two of those groups reported cooking together on Sundays. The largest and smallest groups were unusual with the smallest group (3 people) cooking together every night and the largest group (30 people) assigning a small group of people to cook for the larger dinner group.

Most groups met four times a week, Monday through Thursday. This frequency allowed for groups of eight or twelve that were easily split between the four days the group ate each week. This allowed for each person to always cook on the same day of the week, so person one cooked every other Monday, person two cooked every other Tuesday etc. Many participants said this kind of schedule made it easier to remember when they cooked. To adjust for group size some groups added Sunday meals, skipped a night every other week, or just rotated so the day of the week they cooked was always changing. In most cases the groups made a calendar showing when each person cooked so that they could remember their assignments. Because many groups 
tried to keep a consistent size they had a rule that if someone dropped out they had to find someone to replace them. Most groups didn't have anyone drop out and those who did had no problem finding people who wanted to join. Many participants mentioned having people join or ask if they could join during the semester.

Most groups had a set time they met. A few said they would text to tell people when dinner was done, but even then dinner usually was about the same time each night. Most of the groups started dinner between 6:00 and 7:30 PM. Many groups had a take-home system in place to save food for people who could not come when dinner was served to pick up later. Groups varied on this practice with some not doing it all, some only did it if someone called and asked for it earlier in the day, and a few automatically saved food. Most groups also required people to bring their own plates and silverware that they each would take home and wash. This helped to ease the cleanup work for the cook. Some groups mentioned eating at the table while other groups had so many people that they ate on the couch or wherever there was room to sit.

The people in each dinner group usually lived very close to each other (less than five minutes walking distance). Most groups had about the same number of males and females. People did not pool money but each person paid for the meal that they made. Most groups said it was up to the individual to decide how much they spent on a meal, and very few people mentioned setting an expected price, such as $\$ 20$ a meal. Participants estimated that they spent from \$5-30 dollars per week (mean \$12.88) on food for the dinner group. All groups ate only the dinner meal together except one which also ate breakfast together on Sundays.

There was not a carefully articulated standard for what to include in the meal but most participants mentioned that there were unspoken rules. People expected a home-cooked meal that included a main dish and some sides, usually including a vegetable and sometimes a fruit. This 
standard was usually set by the first few people who cooked and the rest of the dinner group would follow the precedent. Only one participant mentioned having to talk to group members about what was a "full meal.” The rest of the participants said that people knew what a "real meal," "well rounded meal," or "family dinner type meal” was. Participants said that though some dinners were less expensive or simpler than others they felt that it evened out over the semester. The most frequently mentioned standard was to have enough food for everyone. People also expected variety so if someone made spaghetti on Monday, other members of the group tried not to cook the same entrée too soon. Some people came to the dinner group and asked what other people were making that week to avoid repeats close together.

\section{Environmental, Behavioral, and Personal Benefits}

General Positive Comments. There were many positive comments made about dinner groups in general. Most people said that they either really like or love their dinner group, and that it is something that they look forward to everyday. A majority of participants made comments that although there can be difficulties, the benefits made participation worth it. Every one of the participants said that they would participate in a dinner group next semester, but a few qualified that statement by saying they would join a dinner group as long as their schedule permitted. Many participants stated that they thought that if people just knew about dinner groups they would join them.

"I'll get frustrated, but really the benefits outweigh the negative for sure. I love it." "I think getting the word out and introducing people to [dinner groups], people will wanna do it and make it a good experience." 
"It's something I look forward to everyday so not having that in my life would be really depressing. I'd probably starve. (laugh)"

"It's really fun. It's been a very good experience for me."

Cooking. Many students commented that being in a dinner group improved their cooking skills and their confidence in cooking. Learning time management when preparing meals was the skill mentioned most frequently. Other specific skills students mentioned included cooking meat, using spices, or improvising. Some students also mentioned learning social skills related to hosting large numbers of guests (8 people or more).

"I've been able to prove to myself that I am confident and competent."

"I think you learn...time management skills and...having a dinner ready by a certain time."

“You just learn how to use a kitchen and how it really works. You've watched your mom your whole life but you never realized how big of a genius she was."

Cooking for One. When participants cooked just for themselves they said they would usually do something quick and easy, such as making a sandwich. Each person identified foods that they considered to be quick and easy which they ate frequently. Some participants also said that they usually did not eat as well when they were eating alone, often relying on fast food and convenience foods. A few participants also recognized that their meals were not usually planned when they were eating alone, but they were planned when they were cooking for the dinner group. Some participants also mentioned that they did not want to put as much effort into cooking for one as they did when they were cooking for others. 
"So I got really sick of chicken and salad. But I mean it was easy and it was fast and it was something I could do really quick and I didn't have to think about it a lot.” "I find that when I am cooking for myself or when I don't have time, then I don't eat as well.”

"I don't like putting effort into it because it feels like unless I'm cooking for a bunch of people, it's not worth it."

Recipes. Many of the participants mentioned getting recipes by calling family members, usually their mothers, and using websites such as www.allrecipes.com. Most participants found recipes that they didn’t already have, but a few participants liked to stick with cooking foods they already knew how to make. A few participants said that their groups encouraged them to try new things. Many participants also mentioned sharing recipes with each other. One student mentioned having a dinner group blog, and another mentioned creating a dinner group recipe book. Some participants also mentioned that they were compiling recipes that would be useful for cooking in the future.

"Whenever someone else cooks, and they make something really good, then I always like to learn what it is or what they did, and that's fun."

"I really don't like to cook off a recipe, I'd rather have an idea and then I'll look at a bunch of recipes and then kind of experiment and make it and see what works."

Social. Many of the focus group participants mentioned that the social aspect of a dinner group was a motivation for them joining and also many said that the social interaction was their favorite part of being in a dinner group. Participants either wanted to get to know new people or 
spend more time with people they already knew. Many participants commented that they enjoyed the chance to eat with other people and the opportunity to talk to other group members. Nearly all participants mentioned that they became really good friends with their group and felt very close to them by the end of the semester. In every focus group students mentioned that eating dinner together created some kind of a family atmosphere.

"That's probably the main reason I did it, was to get to know people and to interact with people every day."

"It was like eating with your family every night...We all became really good friends because we just ate together every night."

"It's the time where we can be together and just...laugh and tell stories because we sit down at the table and you don't really have time otherwise so, it's been really good for our roommate relationships."

"If I'm not there when the rest of the apartment is eating I usually get my food and take it into a room with somebody else so that I still feel like I am eating with someone."

Money. Saving money was mentioned by some focus group participants as a benefit of being in a dinner group, and a few other students also mentioned the cost effectiveness of eating better quality meals. A few participants thought they were saving money but weren't sure, and one participant said that being in a dinner group does not save money. Cost was not a barrier to joining a dinner group and a few people mentioned saving money as a reason for joining or a way of convincing people to join. A few also said they learned about meal costs in a dinner group. 
“..we have to cook once every three weeks then, that's like never, I mean that's you know four times the whole semester so, it's like free meals."

“...I have twelve dinners for like twenty to thirty dollars, good dinners.”

"I learned a little bit about like, meal cost...but it's been fun to see how little you can spend on a really good meal...”

Variety and Health. Many participants noted that variety was expected in their dinner groups. Some of the focus group participants mentioned the benefit of increased variety in their diet. Variety was often mentioned in conjunction with eating more healthy foods. Many participants felt that they ate healthier meals in a dinner group. This included eating more home-cooked meals and more fruits and vegetables. Students also mentioned increased motivation to eat healthfully.

“I just ate a better variety, I wasn't eating the same thing for dinner every single night just because it was easy to fix.”

“...people wanna have healthy meals...”

“If I'm preparing a meal for a group of people, I'm more motivated, instead of, if it was just me, I wouldn't really want to cook this nice meal just for myself. So, I've just been eating better, probably more well-rounded meals.”

Saving Time. Some students mentioned saving time as a reason for joining as well as a benefit of participation. A few mentioned that they were initially worried about the group taking too much time each night for dinner, but in reality they didn't find that to be the case.

"Other than the day you actually cook, it saves you a ton of time." 
“But it also saves me a lot of time because every night I don't have to think about what I am making myself.”

“Obviously there's time when you're really busy, where you know you have to get to school or get somewhere, so you just come and get your food and leave, but we expect people to stay and eat, provided that they can.”

\section{Environmental, Behavioral, and Personal Difficulties}

General Negative Comments. Some participants mentioned that it is hard initially to make the time commitment to being at a certain place "every night” for the entire semester but they found that it worked out. Some also said that the social aspect took longer than dinner would if they were eating alone. Several participants mentioned stresses that exist on the night they cook, including planning, getting food done on time, and worrying about people liking the food. Another difficulty is relying on people: group members may not show up to eat, may not uphold the group standard for meals when they are cooking, or on the rare occasion someone may completely forget it was their night to cook. A few people mentioned the food served was not food they would eat on their own.

"If I didn't have a dinner group, I might just stay on campus to study where I am more productive, but I wanna go home because I wanna eat, and then I'm less productive in some way, especially because I stay there and I just talk for like an hour.”

“The most pressure that I'll feel, like I'm not nervous about the meal, it's just like will I finish on time and will my apartment look nice enough for people to be able to eat." 
"I'm kind of scared to try new things sometimes because I don't want to make something bad.”

“We have people that don't uphold the standards of our group so they'll like order pizza, which is like a big no."

\section{DISCUSSION}

An important component of the ecSatter model is eating context in which meals are planned and structured. ${ }^{18}$ Many participants mentioned that their dinner group had a set time and place for dinner and they reported spending more time on meal planning and preparation for their dinner group. When cooking for themselves they would usually do something quick and easy and perceived that they did not eat as well. This is consistent with other findings among college students, that "fast and convenient" was a reason for eating at fast-food restaurants, and that getting fast food was easier than preparing a meal just for themselves. ${ }^{4}$ Eating on the run has been associated with increased intakes of soft drinks, fast food, and total and saturated fat, ${ }^{6}$ while meeting dietary guidelines has been inversely associated with frequency of fast food consumption. ${ }^{13}$ Home food preparation is also important because not planning family meals was associated with lower fruit and vegetable intake. ${ }^{21}$

Focus group participants reported increased confidence in cooking, which is likely a manifestation of the SCT construct, self-efficacy. Confidence can be increased through repeated practice in cooking, observation of other participants, and encouragement from other participants, ${ }^{20}$ all of which could occur in a dinner group setting. Increased confidence could be 
important in encouraging college students to spend more time on meal preparation. ByrdBredbenner found that more than one third of students, primarily freshmen and sophomores, rarely or never prepared a meal, ${ }^{7}$ but residence was not reported so many of the students could have been living at home or in residence halls without cooking facilities. Some focus group participants in the present study reported that their cooking skills improved being in a dinner group, while others said being in a dinner group just made them more aware of skills they already had. Byrd-Bredbenner also found that as students reported having more experience with meal preparation they felt more positively about cooking from scratch. ${ }^{7}$ Similarly in the present study students reported that they felt more confident using recipes and trying new things after having some experience. Young adults involved in food preparation have been found to be more likely to meet the dietary guidelines of Healthy People 2010, including consuming more servings of fruits and vegetables. ${ }^{2}$

Participants from our study either wanted to get to know new people or spend more time with people they already knew. This is consistent with other findings that young adults see social eating as important, enjoyable, and valued. ${ }^{1,6}$ Participants had an expectation of receiving social benefits from a dinner group, and since social interaction is valued (expectancies) it can be seen as an important motivator for many participants to join. Nearly all participants mentioned becoming very good friends with their group members and feeling close to them through their regular dinner conversations. Family meals can be a time for togetherness and socialization, including conversing and laughing together, creating a sense of unity, identity, and connectedness as a family. ${ }^{22,23}$ In every focus group students mentioned that eating dinner together created a kind of a family atmosphere and a few mentioned laughing together, 
suggesting this type of social eating interaction of students may provide similar benefits abserved in family based meals.

Larson et $\mathrm{al}^{6}$ found that social eating among young adults was associated with greater intake of some healthful foods. In that study social eating was defined as eating with any other person or persons whether it was family, friend, or a significant other. ${ }^{6}$ The definition is ambiguous and may include eating in a cafeteria, at a fast food or other restaurant, or eating family meals at home. Greaney et al used online focus groups asking college students about healthful weight management; they found that social support was especially helpful for females in helping them to eat healthfully. ${ }^{24}$ Other research has demonstrated that more frequent family meals for adolescents is associated with a healthier food intake, including higher intake of fruits, vegetables, and grains as well as more nutrients such as fiber, calcium, iron, and several vitamins. ${ }^{25,26}$ Dinner groups may potentially be a healthful replacement for family meals when young adults move away from home to attend school.

Many focus group participants felt that their dinner group’s home-cooked meals were healthier, including eating more fruits and vegetables. This suggests that encouraging young adults and college students to eat together in dinner groups could actually lead to improved dietary intake, since many young adults are particularly low in their consumption of fruits and vegetables. ${ }^{1}$ In the ecSatter model, food acceptance includes people eating nutritious food through the encouragement of variety, enjoyment of food, and feeling comfortable in trying new foods. In the current study ecSatter's food acceptance construct was evident as students reported eating more variety and trying new foods when eating with their dinner group. ${ }^{18}$ Participants also reported looking forward to meals and enjoying food. 
Focus group participants mentioned that saving time and money were perceived benefits of dinner group participation. Participants said they were able to eat higher quality meals for the amount of time and money that they spent on the meal. Students didn't seem to see cost as a barrier in the dinner group. This addresses the barriers of time and food cost previously reported to healthful eating in young adults. ${ }^{2,24,27}$ Participation in a dinner group may be a way to help college students overcome these barriers to meal preparation and eating healthfully.

A few participants mentioned that they had been worried about the dinner group taking too much time each night for dinner, but in reality they didn't find that to be a problem. It was mentioned that busy schedules was a common reason for people not joining. Busy schedules are not a problem limited to dinner groups but are also a concern parents express regarding family meals. For example, of parents who had family meals, $70 \%$ thought that the family was not too busy to have evening family meals but $50 \%$ said that it was difficult to coordinate children's and adult's schedules to allow for family meal time. ${ }^{21}$

Only a few negative aspects of a dinner group were mentioned. They included stresses that exist on the night each person cooked, such as planning, getting food done on time, and worrying about people liking the food. Another difficulty brought up by participants was relying on members of the group: they may not show up to eat, they may not uphold the group standard, or they may completely forget it was their night to cook. A majority of participants made comments that although there can be difficulties, the benefits made participation worth it and all the participants said that they would do a dinner group next semester if their schedules permitted.

This study has several limitations. One limitation is that the university where this study was done consisted of students who were part of religious social networks (i.e., campus congregations) which helped facilitate the creation of dinner groups. The students also lived in 
very close proximity to each other, making going to each other's apartments for dinner easy and convenient. The study population was also homogenous consisting of only white young adults, which is representative of the university population. Another limitation of the study is that students who had participated in a dinner group and then "quit" could not be identified for interview. The number of students who fall in this category may have been small, making them difficult to locate.

\section{IMPLICATIONS FOR RESEARCH AND PRACTICE}

The SCT identifies environmental and behavioral factors that help explain college students' participation in dinner groups. One environmental factor supporting participation in a dinner group is the social atmosphere in which eating a planned, balanced meal is encouraged and expected. Participants discover through observational learning how others in their situation create meals and include vegetables and fruits. Behavioral changes include learning new cooking skills, accepting new foods in their diets, making the effort to be at the dinner group each night to eat and making the necessary preparations when it is their turn to cook. Personal factors such as self-efficacy are improved through experience and observation, increasing the likelihood that students will continue to participate in them. Expectancies (values) for the benefits of dinner are increased as the social aspects are incorporated into meals. Before participation in a dinner group, students may have had the expectation that dinner could provide health and variety but they did not value these outcomes enough to make the necessary changes to receive those benefits. When the social aspect, which is valued by young adults, ${ }^{1}$ was added to dinner through 
participation in a dinner group, college students prioritized meals and meal preparation more than they previously had. Participants also mentioned being more motivated to make efforts for others than for themselves so if they are feeding others along with themselves they simultaneously improve their own intake. This combination of the change in environmental, behavioral, and personal factors and the resulting behavior change is an example reciprocal determinism.

Since most dinner group participants expect the meals to be homemade or mostly prepared from scratch, students may reduce their reliance on pre-prepared foods and fast food. Promoting dinner groups among college students may be a way of increasing college students' involvement in cooking activities and meal planning, leading to improved skills and potential health benefits. Participation in dinner groups may also be a way of improving college students' dietary intake, but future research would need to assess actual dietary intake. Other research could also be done to determine if dinner groups are occurring among students at other locations and if there are difference or similarities with the dinner groups conducted at BYU.

\section{REFERENCES}

1. Larson NI, Neumark-Sztainer D, Hannan PJ, Story M. Family meals during adolescence are associated with higher diet quality and healthful meal patterns during young adulthood. $J A m$ Diet Assoc. 2007;107:1502-10.

2. Larson NI, Perry CL, Story M, Neumark-Sztainer D. Food preparation by young adults is associated with better diet quality. J Am Diet Assoc. 2006;106:2001-7. 
3. Burke JD, Reilly RA, Morrell JS, Lofgren IE. The university of New Hampshire's young adult health risk screening initiative. J Am Diet Assoc. 2009;109:1751-1758.

4. Morse KL, Driskell JA. Observed sex differences in fast-food consumption and nutrition selfassessments and beliefs of college students. Nutr Res. 2009;29:173-179.

5. Nelson MC, Larson NI, Barr-Anderson D, Neumark-Szainer D, Story M. Disparities in dietary intake, meal patterning, and home food environments among young adult nonstudents, 2- and 4year college students. Am J Public Health. 2009;99:1216-1219.

6. Larson NI, Nelson MC, Neumark-Sztainer D, Story M, Hannan PJ. Making time for meals: meal structure and associations with dietary intake in young adults. J Am Diet Assoc. 2009;109:72-79.

7. Byrd-Bredbenner C. Food preparation knowledge and attitudes of young adults. Top in Clin Nutr. 2004;19:154-63.

8. Levy J, Auld G. Cooking classes outperform cooking demonstrations for college sophomores. J Nutr Educ Behav. 2004;36:197-203.

9. Caraher M, Dixon P, Lang T, Carr-Hill R. The state of cooking in England: the relationship of cooking skills to food choice. Br. Food J. 1999;101:590-609.

10. Driskell JA, Kim YN, Goebel KJ. Few differences found in the typical eating and physical activity habits of lower-level and upper-level university students. J Am Diet Assoc. 2005;105:798-801.

11. Larson NI, Neumark-Szainer DR, Story MT, Wall MM, Harnack LJ, Eisenberg ME. Fast Food intake: longitudinal trends during the transition to young adulthood and correlates of intake. J Adolescent Health. 2008;43:79-86. 
12. Rydell SA, Harnack LJ, Oakes JM, Story M, Jeffery RW, French SA. Why eat at fast-food restaurants: reported reasons among frequent consumers. J Am Diet Assoc. 2008;108:2066-2070. 13. Hertzler A, Frary R. Dietary status and eating out practices of college students. J Am Diet Assoc. 1992;92:867-70.

14. Guthrie JF, Lin B, Frazao E. Role of food prepared away from home in the American diet, 1977-78 versus 1994-96: changes and consequences. J Nutr Educ Behav. 2002;34:140-150.

15. Feldman S, Eisenberg ME, Neumark-Sztainer D, Story M. Associations between watching TV during family meals and dietary intake among adolescents. J Nutr Educ Behav. 2007;39:25763.

16. Neumark-Sztainer D, Story M, Perry C, Casey MA. Factors influencing choices of adolescents: finding from focus-group discussions with adolescents. (Statistical Data Included). $J$ Am Diet Assoc. 1999;926.

17. Story M, Neumark-Sztainer D, French S. Individual and environmental influences on adolescent eating behaviors. J Am Diet Assoc. 2002;102:S40-S51.

18. Satter E. Eating competence: definition and evidence for the Satter eating competence model. J Nutr Educ Behav. 2007;102:S40-S51.

19. Baranowski T, Perry CL, Parcel GS. How individuals, environments, and health behavior interact. In: Glanz K, Rimer BK, Lewis FM, eds. Health Behavior and Health Education: Theory, Research, and Practice. 3rd ed. San Francisco, CA: Jossey-Bass Publishers; 2002.165184.

20. Contento, IR. Foundation in theory and research: facilitating the ability to take action. In: Nutrition Education. Linking Research, Theory and Practice. Jones and Bartlett Publishing; 2007.114-146. 
21. Boutelle KN, Birnbaum AS, Lytle LA, Murray DM, Story M. Associations between perceived family meal environment and parent intake of fruit, vegetables, and fat. J Nutr Educ Behav. 2003;35:24-29.

22. Fulkerson JA, Story M, Neumark-Sztainer D, Rydell S. Family meals: perceptions of benefits and challenges among parents of 8- 10-year-old children. J Am Diet Assoc. 2008;108:706-709. 23. Fulkerson JA, Story M, Mellin A, Leffert N, Neumark-Sztainer D, French SA. Family dinner meal frequency and adolescent development: relationships with developmental assets and highrisk behaviors. J Adolesc Health. 2006;39:337-45.

24. Greaney ML, Less FD, White AA, Dayton SF, Riebe D, Blissmer B, Shoff S, Walsh JR, Greene GW. College students’ barriers and enablers for healthful weight management: a qualitative study. J Nutr Educ Behav. 2009;41:281-286.

25. Neumark-Sztainer D, Hannan PJ, Story M, Croll J, Perry C. Family meal patterns: associations with sociodemographic characteristics and improved dietary intake among adolescents. J Am Diet Assoc. 2003;103:317-22.

26. Videon TM, Manning CK. Influences on adolescent eating patterns: the importance of family meals. J Adolesc Health. 2003;32:365-73.

27. Betts NM, Amos RJ, Keim K, Peters P, Stewart B. Ways young adults view foods. J Nutr Educ. 1997;29:73-79. 
APPENDIX A

Study on College Students' Dinner Groups 


\section{Research Questions}

How are college students conducting dinner groups?

What do college students perceive are the benefits of participation?

What do college students perceive are the difficulties of participation?

\section{Full Review of Literature}

Young Adult Statistics

Studies on young adults and their eating habits are limited in number and scope. Data suggest that a majority of young adults consume diets that are excessive in fat and inadequate in servings of calcium-rich foods, fruits, deep yellow and green vegetables and whole grains. ${ }^{1,2}$ One study found that less than $50 \%$ of females were meeting the recommendations for vitamin $\mathrm{D}$, folate, calcium, potassium, and iron. Males actually ate closer to recommendations but were still around or below $50 \%$ for vitamin D, folate, calcium and potassium. ${ }^{3}$ This study also found that young adults had high rates of being overweight and were at high risk of chronic disease. This was based on high blood pressure values and LDL cholesterol levels. ${ }^{3}$ Interestingly, though young adults are far from meeting dietary recommendations, those who attend a 4-year college eat more frequent meals and have a better intake than those at a 2-year college or nonstudents. ${ }^{4}$

\section{Young Adult Eating Out}

Almost half of the students in one young adult study by Hertzler and Frary ate at fast food locations at least weekly. ${ }^{5}$ It was shown that from adolescence to young adulthood in males there was an increase in the number of males who ate at fast food restaurants frequently. ${ }^{6}$ 
Meeting dietary guidelines was negatively associated with frequency of fast food consumption. ${ }^{5}$ Food that is eaten out contains more total calories as well as more saturated and total fat. ${ }^{7}$ Another study found that students self reported that they thought they ate too much sugar and processed carbohydrates and also thought they ate too much fat, saturated fat and trans fat. ${ }^{8}$ In that same study by Hertzler and Frary, the reason most commonly chosen for eating out was to socialize with friends. ${ }^{5}$ Females have been found that as they worked increased number of hours, frequency of fast food consumption also increased. ${ }^{6}$ This is consistent with a study finding that for more than half of the students, limited time was a reason for choosing fast food. Most participants listed fast and convenient as a reason for eating at fast food, and some chose that getting fast food was easier than preparing a meal just for themselves. Another reason reported for eating out by both males and females included eating out to eat with family and friends. Low cost was also chosen as a reason for eating out. ${ }^{8}$

\section{Young Adults Cooking Meals}

One study found that most all university students reported typically eating dinner. A little more than half ate breakfast and a large majority ate lunch. ${ }^{9}$ Young adults involved in food preparation were more likely to meet the dietary guidelines of Healthy People 2010 including consuming more servings of fruits and vegetables. ${ }^{2}$ Young adults found that barriers to preparing meals included time available to prepare meals, inadequate cooking skills, and not having enough money to buy food. ${ }^{2}$ The top factors affecting students' food choices in another study were in order of frequency convenience, taste, and cost. ${ }^{9}$

Children today are less likely to learn cooking skills in school before leaving home. ${ }^{10}$ Without cooking skills, young adults are prone to eat away from home or eat premade meals. ${ }^{11}$ 
As students have experience with cooking their confidence increases and they often teach what they have learned to others. ${ }^{10}$

In a study where the majority of the participants were freshmen or sophomores, nearly half of them prepared at least one meal each week, but more than one third of the students rarely or never prepared a meal. ${ }^{12}$ This study also found that food preparation knowledge was low among young adults and that they tended to overestimate their knowledge. ${ }^{12}$ Young adults tend to have a positive attitude toward food preparation but are more negative toward preparing food from “scratch.” 12 They also found that although most students didn’t feel positively about cooking from scratch, reporting more frequent meal preparation related to a more positive feeling toward cooking from scratch. ${ }^{12}$

\section{Social Eating}

Meal patterns and structure relate to dietary intake. ${ }^{1}$ Both males and females have rated social eating and meal structure highly, indicating that young adults see these activities as important. $^{1}$

One study of young adults found that social eating was enjoyed and valued and was associated with greater intake of some healthful foods. ${ }^{13}$ In this study social eating was defined as eating with any other person or persons whether it was family, friend, or a significant other. The population for this study was about half students, and it was found that time constraints were a common barrier to sitting down to eat meals. ${ }^{13}$ They also found that young adults felt that eating regular meals is important. ${ }^{13}$ More than half of young adults in this study felt that they often ate on the run, which was associated with increased soft drink, fast food, and total and saturated fat intake. ${ }^{13}$ Another young adult study found that students were more likely than non students to 
report time for food preparation and money to buy food was inadequate. Students also viewed food more in terms of convenience than nutrition. ${ }^{14}$

\section{Adolescents}

One type of social eating that has been studied widely is family meals. Previous studies have found adolescents who eat more frequent family meals have a healthier nutrient intake, including higher intake of fruits, vegetables and grains as well as fiber, calcium, iron and several vitamins. ${ }^{15,16}$ Frequency of family meals was also inversely associated with intake of soft drinks and saturated fat. ${ }^{15,16}$ Skipping meals and participating in fewer family meals was associated with lower intakes of nutrients and food groups, particularly fruits, vegetables and dairy. ${ }^{15}$ When families eat together they may be more likely to prepare well-balanced, nutritious meals, while adolescents eating on their own may rely more on prepackaged convenience foods. ${ }^{17}$ Family meals may provide an opportunity for parents to provide an example of healthy eating and offer healthful food choices. ${ }^{1,18}$ Interactions with family members about food transmit attitudes, preferences, and values. ${ }^{19}$ Family meals during adolescence are significantly associated with greater intakes of healthy foods and important nutrients in young adulthood. ${ }^{1,17}$ Consumption of fruits, vegetables and soft drinks in adolescence is an important predictor of these behaviors in young adulthood. ${ }^{1}$

In the majority of households one parent was in charge of what would be served for dinner. Almost half of parents reported that their children never or rarely helped with dinner preparations. Many parents felt that planning and preparation for meals was challenging and wanted help with these tasks. ${ }^{20}$ Half of adults said they did not usually plan meals ahead of time and not planning ahead was associated with lower fruit and vegetable intake. ${ }^{21} 70 \%$ of adults thought that the family was not too busy to have family meals together in the evening but 50\% 
said that it was difficult to coordinate children's and adult's schedules in order to have family meals. $^{21}$

Many benefits besides dietary intake have been associated with regular family meals. More frequent family meals in adolescence predicted an increased meal structure and priority for social eating in young adulthood. ${ }^{1}$ Family meals can be viewed as a time for togetherness and socialization as a family. ${ }^{22}$ These rituals and repeated behaviors can create a sense of unity, identity, and connectedness. ${ }^{22}$ Most adults said that dinnertime "is usually pleasant and a time to connect and talk with family.” ${ }^{21}$ The most frequently reported reason parents enjoyed family meals was the conversation. Two thirds of parents also reposted feeling togetherness and laughing as a family. ${ }^{20}$ A positive relationship between family meal frequency and social resistance skills, self-esteem, having a sense of purpose, and a positive view of the future suggests adolescents may learn social skills and develop a more positive self-worth during meal interactions. $^{22}$ There are also positive associations between family meal frequency and family support, positive family communication, parental involvement in school, and family boundaries. $^{22}$

Research has consistently found an inverse relationship between frequency of family dinners and many high-risk behaviors, such as substance abuse, low grade point average, depressive symptoms, and disordered eating. ${ }^{23,24,25}$ Two of these studies found that some of these inverse relationships still had an effect after controlling for the effects of family support and communication. ${ }^{22,23,24}$ Family meals were found to be a protective factor to guard against substance use and some of these other high risk behaviors. ${ }^{23,25}$

The current study will look at a specific type of social eating among college students. Young adult dinner groups are a phenomenon that researchers have not found described in any of 
the literature. In order to set the groundwork for future quantitative evaluation of dinner groups, this study will take a qualitative look at dinner groups. For the purpose of this study, dinner groups will be defined as three or more people regularly meeting together at least four times a week to cook and eat together. The purpose of this study will be to identify the different ways that dinner groups are planned, organized, and carried out, and students' perceptions of benefits and difficulties related to participation in dinner groups.

The Social Cognitive Theory (SCT) is a health behavior theory that addresses health behavior as it is influenced by psychosocial dynamics as well as methods for promoting behavior change. According to the SCT, behavior is described as not simply the result of the environment and the person, but is influenced by them and influences them in return. This concept is called reciprocal determinism. It is a dynamic system where a change in one component has an impact on the others. ${ }^{26}$ Other concepts that are part of the Social Cognitive Theory include behavioral capabilities, observational learning, expectations, expectancies and self-efficacy. ${ }^{26,27}$ Behavioral capabilities are the skills and knowledge that are necessary for a person to be able to perform an action. ${ }^{26}$ An example of this relating to dinner groups would be students' knowledge of shopping and cooking skills. Observational learning occurs when a person watches the action of another person and sees the outcomes of that behavior. ${ }^{27}$ This could occur in dinner groups as group members see other group members making and serving meals. Expectancies and expectations are interrelated and often hard to keep straight. While expectations are the outcomes that are anticipated the expectancy is the importance given to that outcome. ${ }^{26}$ For a dinner group, a student could expect that he will get social interaction from participation, while the expectancy is that the social interaction will make his day more enjoyable. The last construct we intend to look at is self-efficacy, which is personal confidence in completing a behavior. Topics and themes 
identified in the focus groups pertaining to dinner groups will be applied to these constructs from the SCT.

\section{Methods}

\section{Phase I- Focus Groups}

Sample Size

The sample included students from Brigham Young University who were currently participating in a dinner group. There were a total of 36 participants involved in seven focus groups.

Approval

Approval was obtained from the Institutional Review Board for Human Subjects (Appendix B) before conducting this study. Appropriate amendments were obtained and renewal was applied for and issued after one year.

Recruitment

The participants were recruited through fliers placed at apartment complexes, announcements in general education classes at BYU and UVU, and through an email sent out through the college of Life Sciences (Appendix C). The email was sent in order to try and find people who had dropped out of a dinner group so that they could be interviewed to determine if they had differing opinions on dinner groups. Interested college students who were currently participating in dinner groups were directed to a Qualtrics website (Appendix D) where they took 
a survey to determine if were eligible to participate in the focus groups. A dinner group was defined as three or more people cooking for each other (or together) and eating together at least four times a week. Both males and females were included. The Qualtrics survey included days and times available for focus groups. A personal invitation via e-mail was sent back confirming the time and place. There was also a reminder e-mail sent the day before the focus group was held. About 10 participants were recruited for each group with varied attendance at each one.

\section{Focus Group Pilot Test}

There was a pilot focus group. This pilot test was used for the primary moderator to observe another moderator to help develop skills to run a focus group and to determine the appropriateness of the question set in extracting the desired response as well as the flow and sequencing of the questions. The graduate student was trained as a moderator by the graduate faculty advisor as well as by practice in the classroom. The sessions were audio taped and there was an assistant moderator/observer to take notes. Evaluation was done afterwards before proceeding to research study focus groups to work out any problems.

\section{Focus Groups}

There were seven focus groups held with 2 to 10 participants in each. The groups were held on BYU campus in the Eyring Science Center. One or two groups were held per week. The groups were held at various times to be able to accommodate more students' schedules.

At each session the participants were identified by first name only for confidentiality. Each group was run by a moderator (BB) and discussions were tape recorded. An assistant moderator (LBB) was also present to take notes on the discussion. At the beginning of the 
session all participants filled out a short questionnaire of demographic and basic dinner-group information. Participants also signed the consent to be a research subject form and given a copy to take home (Appendix E). After the questionnaires were completed, the moderator led the discussion using the pre-planned questions (Appendix F). Each focus group was approximately an hour and a half long including the time allotted for the questionnaire.

\section{Evaluation}

Immediately following each focus group the moderator and assistant moderator discussed the group and ideas that seemed to them to be most prevalent in the group. The recorded focus group discussions were then transcribed verbatim. This was done during the next few months.

After the fourth group we evaluated and determined it was necessary to continue with a few more focus groups. A few more focus groups were scheduled and at the end of seven focus groups we determined that we had heard all the new information and insights on dinner groups.

\section{Analysis}

The focus group transcripts were coded by topics, and themes and subthemes were identified (Appendix G). This evaluation was done independently by two researchers. Any discrepancies between researchers in coding were reconciled and common themes that emerge were discussed. The program NUDIST Nvivo (v. 8, 2008, Melbourne, Australia) was used to code focus group comments. This software allows researchers to electronically code and sort responses from participants for management of data and manuscript preparation. The information from the demographics questionnaire was summarized and charted using descriptive statistics including means and frequencies. 


\section{Phase II- Survey}

Based on the formative information collected in the focus groups a survey (Appendix $\mathrm{H}$ ) was developed that can be used to describe dinner groups among college students. The survey consisted of 71 questions, with 55 questions using Likert scales to describe the feelings of dinner group participants. The remaining questions described dinner group organization and demographics of participants. The focus group participants were contacted and asked if they were willing to be part of a pilot test of the survey and distribute the survey to their current dinner group if they are still participating in a group. The survey was administered to a total of 58 students, including about 8 of the original focus group participants. Response distributions and mean scores were calculated for each question and these values were placed in a chart. 


\section{Results}

\section{Phase I- Focus Groups}

\begin{tabular}{|c|c|}
\hline Sex & \\
\hline Male & 8 \\
\hline Female & 28 \\
\hline \multicolumn{2}{|l|}{ Age (y) } \\
\hline Range & $19-26$ \\
\hline Mean & 21.6 \\
\hline \multicolumn{2}{|l|}{ Employment } \\
\hline Unemployed & 13 \\
\hline Employed & 23 \\
\hline \multicolumn{2}{|l|}{ Year in School } \\
\hline Freshman & 2 \\
\hline Sophomore & 8 \\
\hline Junior & 12 \\
\hline Senior & 9 \\
\hline Graduate Student & 5 \\
\hline \multicolumn{2}{|l|}{ Credits (hr) } \\
\hline Range & $9-18$ \\
\hline Mean & 14.3 \\
\hline
\end{tabular}

\begin{tabular}{|l|c|}
\hline $\begin{array}{l}\text { Table 2. Questionnaire Dinner } \\
\text { Characteristics }\end{array}$ \\
\hline Time in a Dinner Group (sem) \\
\hline Range & $1-11$ \\
\hline Mean & 2.6 \\
\hline Days Eating Together & \\
\hline Range & $4-7$ \\
\hline Mean & 4.5 \\
\hline Number of People & \\
\hline Range & $3-30$ \\
\hline Mean & 8.8 \\
\hline
\end{tabular}




\section{Phase II- Survey}

\begin{tabular}{|l|c|}
\hline $\begin{array}{l}\text { Table 3. Survey Demographic } \\
\text { Characteristics }\end{array}$ \\
\hline Sex & \\
\hline Male & 24 \\
\hline Female & 34 \\
\hline Age (y) & \\
\hline Range & $19-32$ \\
\hline Mean & 23 \\
\hline Employment & \\
\hline Unemployed & 12 \\
\hline Employed & 46 \\
\hline Year in School & \\
\hline Freshman & 1 \\
\hline Sophomore & 5 \\
\hline Junior & 10 \\
\hline Senior & 22 \\
\hline Graduate Student & 9 \\
\hline Non-student & 11 \\
\hline
\end{tabular}




\begin{tabular}{|l|c|}
\hline $\begin{array}{l}\text { Table 4. Survey Dinner Group } \\
\text { Characteristics }\end{array}$ \\
\hline Time in a Dinner Group (sem) & \\
\hline Range & $1-13$ \\
\hline Mean & 5.8 \\
\hline Number of People & 2 \\
\hline $3-4$ & 7 \\
\hline $5-6$ & 7 \\
\hline $7-8$ & 1 \\
\hline $9-10$ & 39 \\
\hline $11-12$ & 2 \\
\hline$>12$ & \\
\hline Days Eating Together & 50 \\
\hline 4 days a week & 7 \\
\hline 5 days a week & \\
\hline People in Group & 8 \\
\hline Only roommates & 33 \\
\hline Roommates and Others & 17 \\
\hline Only others & \\
\hline Time Spent on Preparation & 20 \\
\hline $0-2$ hours & 36 \\
\hline 2-4 hours & 2 \\
\hline$>2$ hours & 20 \\
\hline Time Spent on Eating & 34 \\
\hline $0-30$ minutes & 3 \\
\hline $30-60$ minutes & \\
\hline $60-90$ minutes & \\
\hline$>90$ minutes & \\
\hline
\end{tabular}




\begin{tabular}{|c|c|c|c|c|c|c|}
\hline Question & Mean & $\begin{array}{c}\mathrm{SA} \\
\mathrm{n}(\%)\end{array}$ & $\begin{array}{c}A \\
n(\%)\end{array}$ & $\begin{array}{c}U \\
n(\%)\end{array}$ & $\begin{array}{c}D \\
\mathrm{n}(\%)\end{array}$ & $\begin{array}{c}\text { SD } \\
n(\%)\end{array}$ \\
\hline \multicolumn{7}{|l|}{ Reasons for Joining } \\
\hline $\begin{array}{l}\text { Social interaction was a reason I had for joining } \\
\text { a dinner group. }\end{array}$ & 4.3 & $33(57)$ & $17(29)$ & $4(7)$ & $3(5)$ & $1(2)$ \\
\hline $\begin{array}{l}\text { Saving time was a reason I had for joining a } \\
\text { dinner group. }\end{array}$ & 4.00 & $25(43)$ & $21(36)$ & $3(5)$ & $5(9)$ & $4(7)$ \\
\hline $\begin{array}{l}\text { Saving money was a reason I had for joining a } \\
\text { dinner group. }\end{array}$ & 3.9 & $23(40)$ & $20(34)$ & $5(9)$ & 9 (16) & $1(2)$ \\
\hline $\begin{array}{l}\text { Eating healthier was a reason I had for joining a } \\
\text { dinner group. }\end{array}$ & 3.9 & $20(34)$ & $20(34)$ & $6(10)$ & $11(19)$ & $0(0)$ \\
\hline $\begin{array}{l}\text { Eating a better variety of foods was a reason I } \\
\text { had for joining a dinner group. }\end{array}$ & 3.9 & $18(31)$ & $25(43)$ & 9 (16) & $5(9)$ & $1(2)$ \\
\hline $\begin{array}{l}\text { Eating Dinner or Main Meal Alone } \\
\text { When I eat alone I eat a lot of the same things }\end{array}$ & & & & & & \\
\hline over and over. & 4.3 & $22(38)$ & $34(59)$ & $2(3)$ & $0(0)$ & $0(0)$ \\
\hline $\begin{array}{l}\text { When I eat alone it is hard to think of something } \\
\text { to eat every day. }\end{array}$ & 3.9 & $11(19)$ & $37(64)$ & $4(7)$ & $6(10)$ & $0(0)$ \\
\hline $\begin{array}{l}\text { When I eat alone I eat a lot of convenience } \\
\text { foods. }\end{array}$ & 3.9 & $19(33)$ & $27(47)$ & $4(7)$ & $4(7)$ & $4(7)$ \\
\hline $\begin{array}{l}\text { When I eat alone I make large portions of one } \\
\text { thing and eat the leftovers until it is gone. }\end{array}$ & 3.4 & 9 (16) & $27(47)$ & $3(5)$ & $16(28)$ & $3(5)$ \\
\hline $\begin{array}{l}\text { When I eat alone I don't eat very healthy. } \\
\text { When I eat alone I don't feel I have enough }\end{array}$ & 3.1 & $8(14)$ & $17(29)$ & $7(12)$ & $15(26)$ & $6(10)$ \\
\hline money to make dinner every night. & 2.8 & $6(10)$ & $14(24)$ & $9(16)$ & $21(36)$ & $8(14)$ \\
\hline $\begin{array}{l}\text { When I eat alone I eat on campus a lot. } \\
\text { Eating Habits and Skills }\end{array}$ & 2.5 & $5(9)$ & $12(21)$ & $6(10)$ & $21(36)$ & $14(24)$ \\
\hline $\begin{array}{l}\text { My cooking skills have increased since I joined a } \\
\text { dinner group. }\end{array}$ & 3.8 & $13(22)$ & $27(47)$ & $10(17)$ & $7(12)$ & $0(0)$ \\
\hline $\begin{array}{l}\text { My confidence in my cooking has increased } \\
\text { since joining a dinner group. }\end{array}$ & 3.7 & $14(24)$ & $24(41)$ & $8(14)$ & $10(17)$ & $1(2)$ \\
\hline $\begin{array}{l}\text { How I eat outside of my dinner group has not } \\
\text { changed since being in a dinner group. } \\
\text { My food habits outside of my dinner group have }\end{array}$ & 3.2 & $3(5)$ & $25(43)$ & $9(16)$ & $18(31)$ & $2(3)$ \\
\hline improved since joining the dinner group. & 2.9 & $2(3)$ & $14(24)$ & $21(36)$ & $19(33)$ & $1(2)$ \\
\hline
\end{tabular}




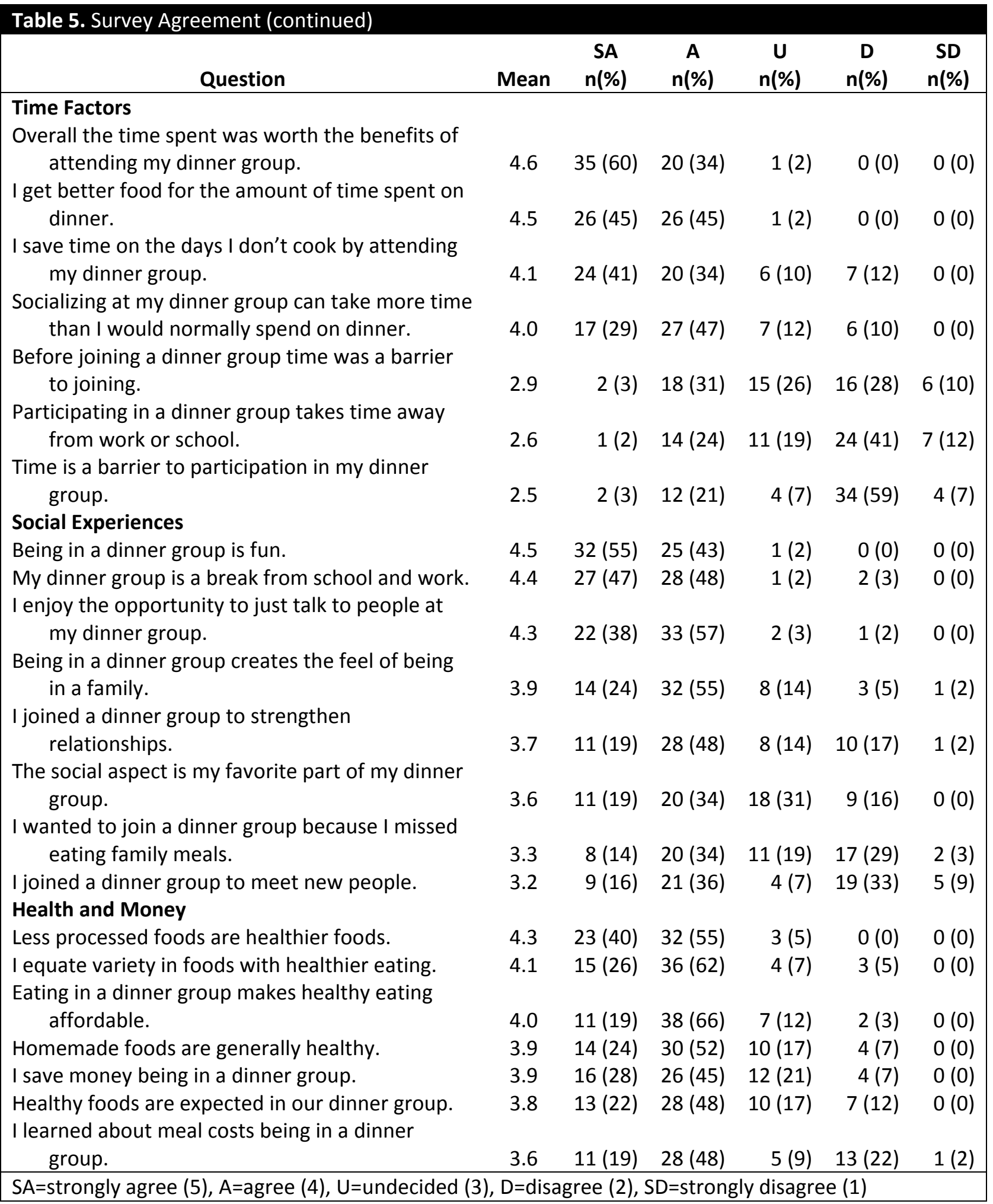




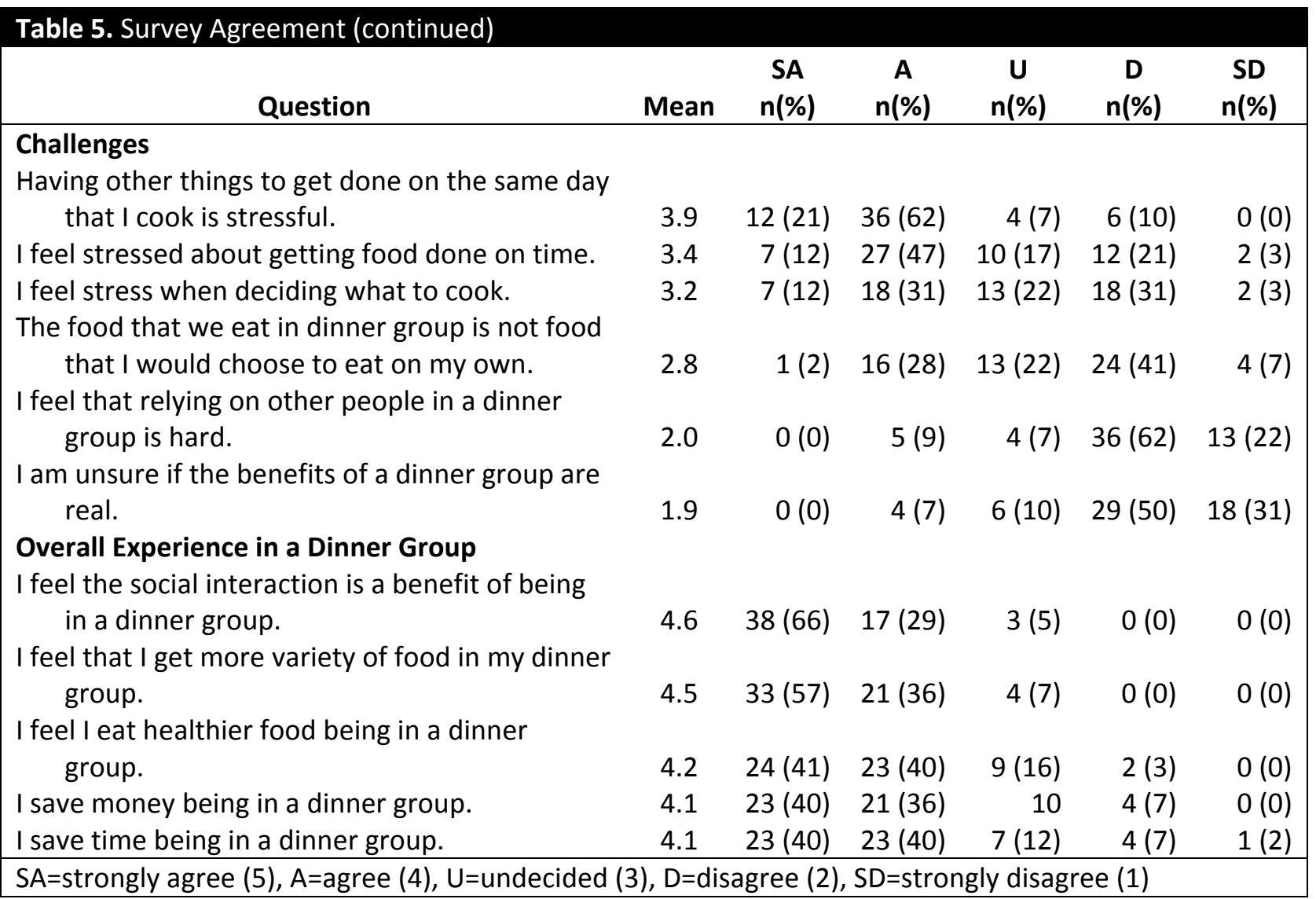

\section{Table 6. Survey Frequencies}

\begin{tabular}{|c|c|c|c|c|c|c|c|}
\hline Question & Mean & $\begin{array}{c}A \\
n(\%)\end{array}$ & $\begin{array}{c}V F \\
n(\%)\end{array}$ & $\begin{array}{c}0 \\
n(\%)\end{array}$ & $\begin{array}{c}R \\
n(\%)\end{array}$ & $\begin{array}{c}\text { VR } \\
n(\%)\end{array}$ & $\begin{array}{c}N \\
n(\%)\end{array}$ \\
\hline \multicolumn{8}{|l|}{$\begin{array}{l}\text { Other People } \\
\text { I worry about people liking the food }\end{array}$} \\
\hline I prepare. & 4.1 & $5(9)$ & $17(29)$ & $26(45)$ & $5(9)$ & $1(2)$ & $4(7)$ \\
\hline People don't help clean up. & 3.5 & $4(7)$ & $15(26)$ & $16(28)$ & $6(10)$ & $3(5)$ & $14(24)$ \\
\hline $\begin{array}{l}\text { I feel like our dinner group is a } \\
\text { competition and/or there is }\end{array}$ & & & & & & & \\
\hline pressure to be the best cook. & 2.2 & $2(3)$ & $0(0)$ & $8(14)$ & $11(19)$ & $15(26)$ & $22(38)$ \\
\hline cooking. & 2.2 & $0(0)$ & $1(2)$ & $11(19)$ & $10(17)$ & $12(21)$ & $24(41)$ \\
\hline $\begin{array}{l}\text { People don't uphold the food } \\
\text { standards. }\end{array}$ & & & & $9(16)$ & & & $26(15)$ \\
\hline People forget it's their night. & $\begin{array}{l}2.1 \\
1.9\end{array}$ & $0(0)$ & $\begin{array}{l}1(2) \\
1(2)\end{array}$ & $\begin{array}{r}9(10) \\
2(3)\end{array}$ & $\begin{array}{l}11(19) \\
12(21)\end{array}$ & $\begin{array}{l}11(19) \\
16(28)\end{array}$ & $\begin{array}{l}20(45) \\
27(47)\end{array}$ \\
\hline
\end{tabular}




\section{Discussion}

\section{Phase I- Focus Groups}

There were no people found who had dropped out of a dinner group mid-semester. The only people who responded to the email were people who dropped out at the end of a semester, but intended to continue with a dinner group once their schedule permitted. One drop-out was referred by a focus group member but was unable to come to the scheduled interview.

\section{Phase II- Survey}

The survey supported and helped clarify many of the focus group results (see Table 5). Surveyed students agreed that the reasons they had for joining a dinner group included saving time, saving money, eating healthier, eating a better variety of foods, and social interaction. The mean scores for agreement for these same factors increased when asked about benefits after joining, suggesting that participants received additional benefits or the benefits in a greater magnitude than they had expected before joining.

Not a single person disagreed that social interaction was a benefit of being in a dinner group. From the focus group it appeared that most people joined in order to meet new people but the survey results showed that more people may join to strengthen relationships. Also, no one disagreed with the statement that a dinner group is fun.

For the most part, surveyed respondents agreed with the focus groups’ comments about eating alone. Survey respondents disagreed that they ate on campus and mean scores were neutral about not having enough money to eat and not eating healthfully. Also no students disagreed that they ate a lot of the same foods over and over again confirming that this is a 
common practice among college students. This helps to clarify which of the habits mentioned by students in the focus group were most prevalent among students when eating alone.

The survey supported the initial conclusion that dinner group participation increased students’ perceptions of their cooking skills and confidence. Most participants thought that healthy foods were expected in their dinner group and that eating in a dinner group made eating healthfully more affordable. Further, no one disagreed with the statement that they got more variety in a dinner group.

Participants were spilt about whether or not time was a barrier before joining a dinner group. This confirms what was found in the focus groups as some participants mentioned time being a barrier and others believe it was a reason to join. The beliefs that being in a dinner group was worth the time spent and that they got better food for the amount of time spent on dinner were strongly supported by the survey.

When asked about negatives, survey respondents mostly disagreed with the negative statements confirming that they were not experienced frequently. People said that very rarely someone forgot it was their night to cook, which was not surprising because focus group comments suggested that it only happened once a semester or not at all. The stresses similar to those in the focus group were having things to get done on the same day they cook and to a lesser degree getting food done on time. Participants also said they occasionally worried about people liking the food they prepared and rarely or occasionally people didn’t help clean up. Expectations about helping to clean up seemed to vary with each group so this may not be a complaint but a statement of fact, since in the focus groups people often said it was not expected that people help clean up but it was appreciated and participants expressed wanting more help with cleaning. 


\section{References}

1. Larson NI, Neumark-Sztainer D, Hannan PJ, Story M. Family meals during adolescence are associated with higher diet quality and healthful meal patterns during young adulthood. J Am Diet Assoc 2007;107:1502-10.

2. Larson NI, Perry CL, Story M, Neumark-Sztainer D. Food preparation by young adults is associated with better diet quality. J Am Diet Assoc 2006;106:2001-7.

3. Burke JD, Reilly RA, Morrell JS, Lofgren IE. The university of New Hampshire’s young adult health risk screening initiative. J Am Diet Assoc. 2009;109:1751-1758.

4. Nelson MC, Larson NI, Barr-Anderson D, Neumark-Szainer D, Story M. Disparities in dietary intake, meal patterning, and home food environments among young adult nonstudents, 2- and 4year college students. Am J Public Health. 2009;99:1216-1219.

5. Hertzler A, Frary R. Dietary status and eating out practices of college students. J Am Diet Assoc 1992;92:867-70.

6. Larson NI, Neumark-Szainer DR, Story MT, Wall MM, Harnack LJ, Eisenberg ME. Fast Food intake: longitudinal trends during the transition to young adulthood and correlates of intake. J Adolescent Health. 2008;43:79-86.

7. Guthries JF, Lin B, Frazao E. Role of food prepared away from home in the american diet, 1977-78 versus 1994-96: changes and consequences. J Nutr Educ Behav. 2002;34:140-150.

8. Morse KL, Driskell JA. Observed sex differences in fast-food consumption and nutrition selfassessments and beliefs of college students. Nutr Res. 2009;29:173-179. 
9. Driskell JA, Kim YN, Goebel KJ. Few differences found in the typical eating and physical activity habits of lower-level and upper-level university students. J Am Diet Assoc. 2005;105:798-801.

10. Levy J, Auld G. Cooking classes outperform cooking demonstrations for college sophomores. J Nutr Educ Behav. 2004;36:197-203.

11. Caraher M, Dixon P, Lang T, Carr-Hill R. The state of cooking in England: the relationship of cooking skills to food choice. Br. Food J. 1999;101:590-609.

12. Byrd-Bredbenner C. Food preparation knowledge and attitudes of young adults. Topics in Clinical Nutrition 2004;19:154-63.

13. Larson NI, Nelson MC, Neumark-Sztainer D, Story M, Hannan PJ. Making time for meals: meal structure and associations with dietary intake in young adults. J Am Diet Assoc 2009;109:72-79.

14. Betts NM, Amos RJ, Keim K, Peters P, Stewart B. Ways young adults view foods. J Nutr Educ 1997;29:73-79.

15. Neumark-Sztainer D, Hannan PJ, Story M, Croll J, Perry C. Family meal patterns: associations with sociodemographic characteristics and improved dietary intake among adolescents. J Am Diet Assoc 2003;103:317-22.

16. Videon TM, Manning CK. Influences on adolescent eating patterns: the importance of family meals. J Adolesc Health 2003;32:365-73.

17. Feldman S, Eisenberg ME, Neumark-Sztainer D, Story M. Associations between watching TV during family meals and dietary intake among adolescents. J Nutr Educ Behav 2007;39:25763.

18. Neumark-Sztainer D, Story M, Perry C, Casey MA. Factors influencing choices of 
adolescents: finding from focus-group discussions with adolescents. (Statistical Data Included). $J$ Am Diet Assoc. 1999;926.

19. Story M, Neumark-Sztainer D, French S. Individual and environmental influences on adolescent eating behaviors. J Am Diet Assoc. 2002;102:S40-S51.

20. Fulkerson JA, Story M, Neumark-Sztainer D, Rydell S. Family meals: perceptions of benefits and challenges among parents of 8- 10-year-old children. J Am Diet Assoc. 2008;108:706-709. 21. Boutelle KN, Birnbaum AS, Lytle LA, Murray DM, Story M. Associations between perceived family meal environment and parent intake of fruit, vegetables, and fat. J Nutr Educ Behav. 2003;35:24-29.

22. Fulkerson JA, Story M, Mellin A, Leffert N, Neumark-Sztainer D, French SA. Family dinner meal frequency and adolescent development: relationships with developmental assets and highrisk behaviors. J Adolesc Health 2006;39:337-45.

23. Eisenberg ME, Olson RE, Neumark-Sztainer D, Story M, Bearinger LH. Correlations between family meals and psychosocial well-being among adolescents. Arch Pediatr Adolesc Med 2004;158:792-6.

24. Neumark-Sztainer D, Wall M, Story M, Fulkerson JA. Are family meal patterns associated with disordered eating behaviors among adolescents? J Adolesc Health 2004;35:350-9.

25. Eisenberg ME, Neumark-Sztainer D, Fulkerson JA, Story M. Family meals and substance use: is there a long-term protective association? J Adolesc Health 2008;43:151-6.

26. Baranowski T, Perry CL, Parcel GS. How individuals, environments, and health behavior interact. In: Glanz K, Rimer BK, Lewis FM, eds. Health Behavior and Health Education: Theory, Research, and Practice. 3rd ed. San Francisco, CA: Jossey-Bass Publishers; 2002.165184. 
27. Contento, IR. Foundation in theory and research: facilitating the ability to take action. In: Nutrition Education. Linking Research, Theory and Practice. Jones and Bartlett Publishing; 2007.114-146. 
APPENDIX B

IRB Approval 
INSTITUTIONAL REVIEW BOARD FOR

HUMAN SUBJECTS

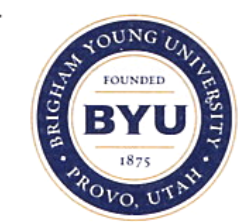

March 11, 2009

Brita Ball

1969 N. Canyon Rd \#211

Provo, UT 84604

Re: Qualitative Description of College Students' Dinner Groups

Dear Brita,

This is to inform you that Brigham Young University's IRB has approved the above research study.

The approval period is from $\mathbf{0 3 / 1 1 / 0 9}$ to $\mathbf{0 3 / 1 0 / 1 0}$. Your study number is X09-0071. Please be sure to reference this number in any correspondence with the IRB.

Continued approval is conditional upon your compliance with the following requirements:

- A copy of the Informed Consent Document, approved as of 03/11/09 is enclosed. No other consent form should be used. It must be signed by each subject prior to initiation of any protocol procedures. In addition, each subject must be given a copy of the signed consent form.

- All protocol amendments and changes to approved research must be submitted to the IRB and not be implemented until approved by the IRB.

- The enclosed recruitment advertisement has been approved. Advertisements, letters, Internet postings and any other media for subject recruitment must be submitted to IRB and approved prior to use.

- A few months before this date we will send out a continuing review form. There will only be two reminders. Please fill this form out in a timely manner to ensure that there is not a lapse in your approval.

If you have any questions, please do not hesitate to call me.

Sincerely,

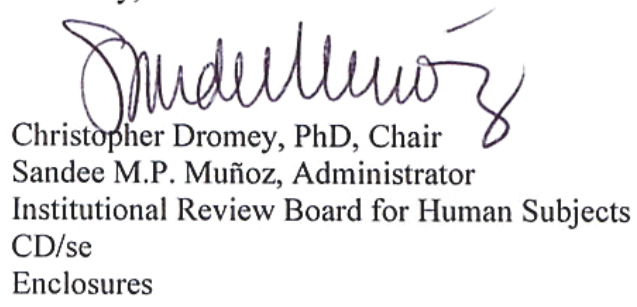

BRIGHAM YOUNG UNIVERSITY · A-285 ASB · PROVO, UTAH 84602 
APPENDIX C

Fliers and Email 


\title{
Are you single and part of a dinner group?
}

Does your dinner group...

Eat home cooked meals

Have 3 or more people

Meet 4 or more times per week

Eat together

\begin{abstract}
You could earn $\$ 10$ for participating in a discussion about your experience.

We need your expertise to help us teach other students about dinner groups.
\end{abstract}

The discussion groups will meet on the BYU campus.

You will be asked to fill out a short questionnaire and then talk about your experience in a dinner group for about an hour.

If you are interested go to

\section{ndfs.byu.edu/home/dinnergroups.aspx}

to learn more and sign up for a discussion group.

The Department of Nutrition, Dietetics and Food Science at Brigham

Young University

Contact Dr. Lora Beth Brown with any questions: Lorabeth_Brown@byu.edu, S-245 ESC

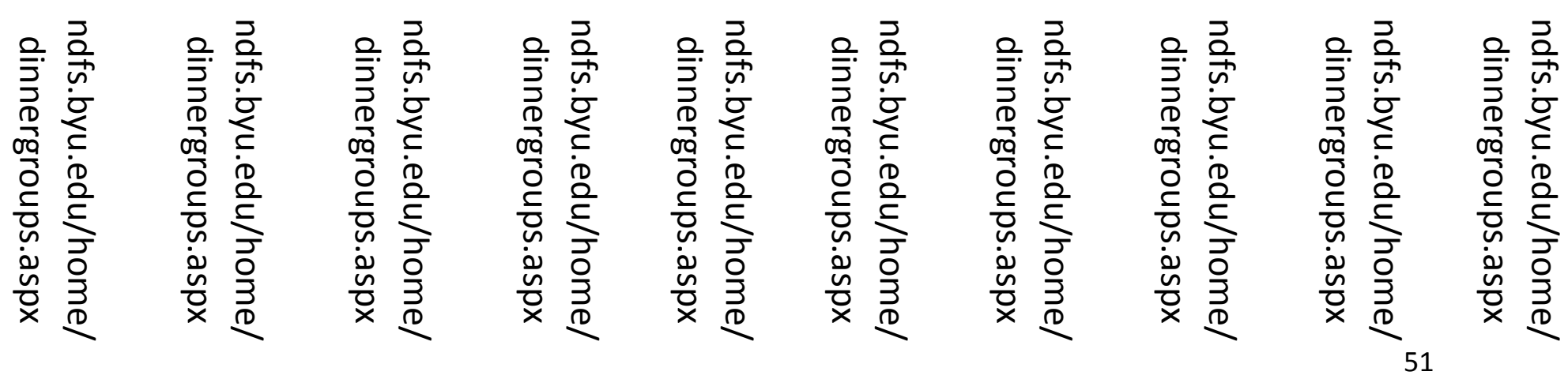


Are you single and part of a

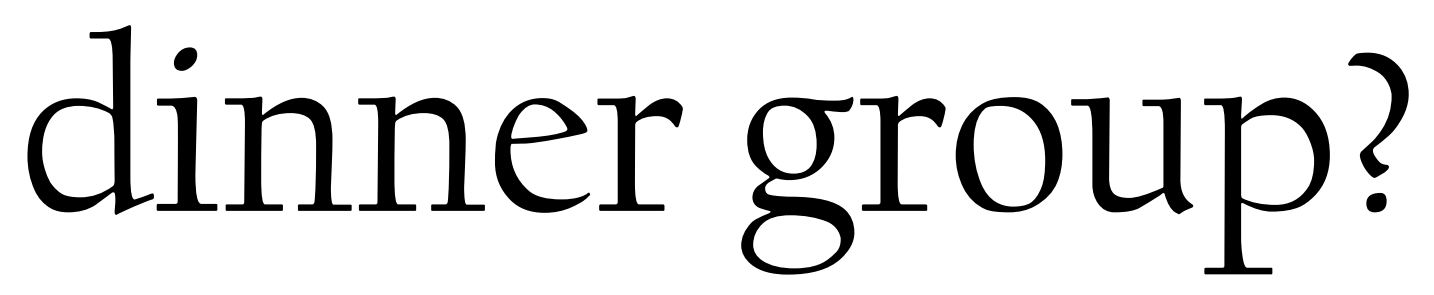

Does your dinner group...

Eat home cooked meals

Have 3 or more people

Meet 4 or more times per week

Eat together

You could earn $\$ 10$ for participating in a

discussion about your experience.

We need your expertise to help us teach other students about dinner groups.

The discussion groups will meet on the BYU campus. You will fill out a short questionnaire and then talk about your experience in a dinner group for about an hour.

\section{If you are interested go to ndfs.byu.edu/home/dinnergroups.aspx to learn more and sign up for a discussion group.}

The Department of Nutrition, Dietetics and Food Science at Brigham Young University 
Life Sciences List Serve Email

\title{
Dinner Group Research Study
}

We are looking for students who were previously in a dinner 8 roup but dropped out, either during the semester or at the end.

The Dinner Group Should Have:

\author{
Eaten home coolked meals \\ Had 3 or more people \\ Met 4 or more times per week \\ Ate together
}

\begin{abstract}
You could earn $\$ 5$ for participating in a 20 to 30 minute interview about your past experience in a dinner 8 roup.
\end{abstract}

Please contact Brita Ball at britamichelle@8mail.com if you are interested. 
APPENDIX D

Qualtrics Website 


\section{BYU}

\section{BRIGHAM YOUNG}

U N I V E R S I T Y

\section{Default Question Block}

Are you currently a full time student?

Yes

No

Where do you attend school?

BYU

$\bigcirc u v u$

Other

Are you currently participating in a dinner group?

Yes

No

Are you married?

Yes

No

Are you currently living at home with your parents?

Yes

No 
Are you currently participating in a meal plan?
Yes
No

How many months have you participated in your current dinner group?

\begin{tabular}{ll}
$\bigcirc$ & $<1$ \\
\hline & 1 \\
\hline & 2 \\
\hline & 3 \\
0 & 4 \\
\hline &
\end{tabular}

How many people are in your current dinner group, including yourself?

How many days a week do you eat with your dinner group?

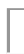

Which of the following times would you be able to meet on BYU campus to discuss your experience in your dinner group?

Wednesday March 4, 2:30-4:00pm
Tuesday March 10, 3:00-4:30pm
Wednesday March 18, 3:00-4:30
Tuesday March 24, 3:00-4:30pm
Tuesday March 31, 4:00-5:30pm
Thursday April 9, 4:00-5:30pm
Tuesday April 14, 5:00-6:30


Please fill out the following:

First and Last Name

Email address

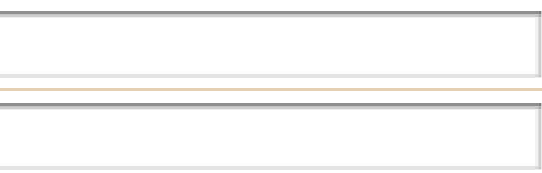

Rank the times in order of your perference

\begin{tabular}{lr} 
» Wednesday March 4, 2:30-4:00pm & $\mathbf{1}$ \\
\hline » Tuesday March 10, 3:00-4:30pm & $\mathbf{2}$ \\
\hline » Wednesday March 18, 3:00-4:30 & $\mathbf{3}$ \\
\hline » Tuesday March 24, 3:00-4:30pm & $\mathbf{4}$ \\
\hline » Tuesday March 31, 4:00-5:30pm & $\mathbf{5}$ \\
\hline » Thursday April 9, 4:00-5:30pm & $\mathbf{6}$ \\
\hline » Tuesday April 14, 5:00-6:30 & $\mathbf{7}$
\end{tabular}

Please list the first names of all the members of your dinner group. This is to try to keep people from the same dinner group from being in the same discussion group. This is important for variety of the discussion.

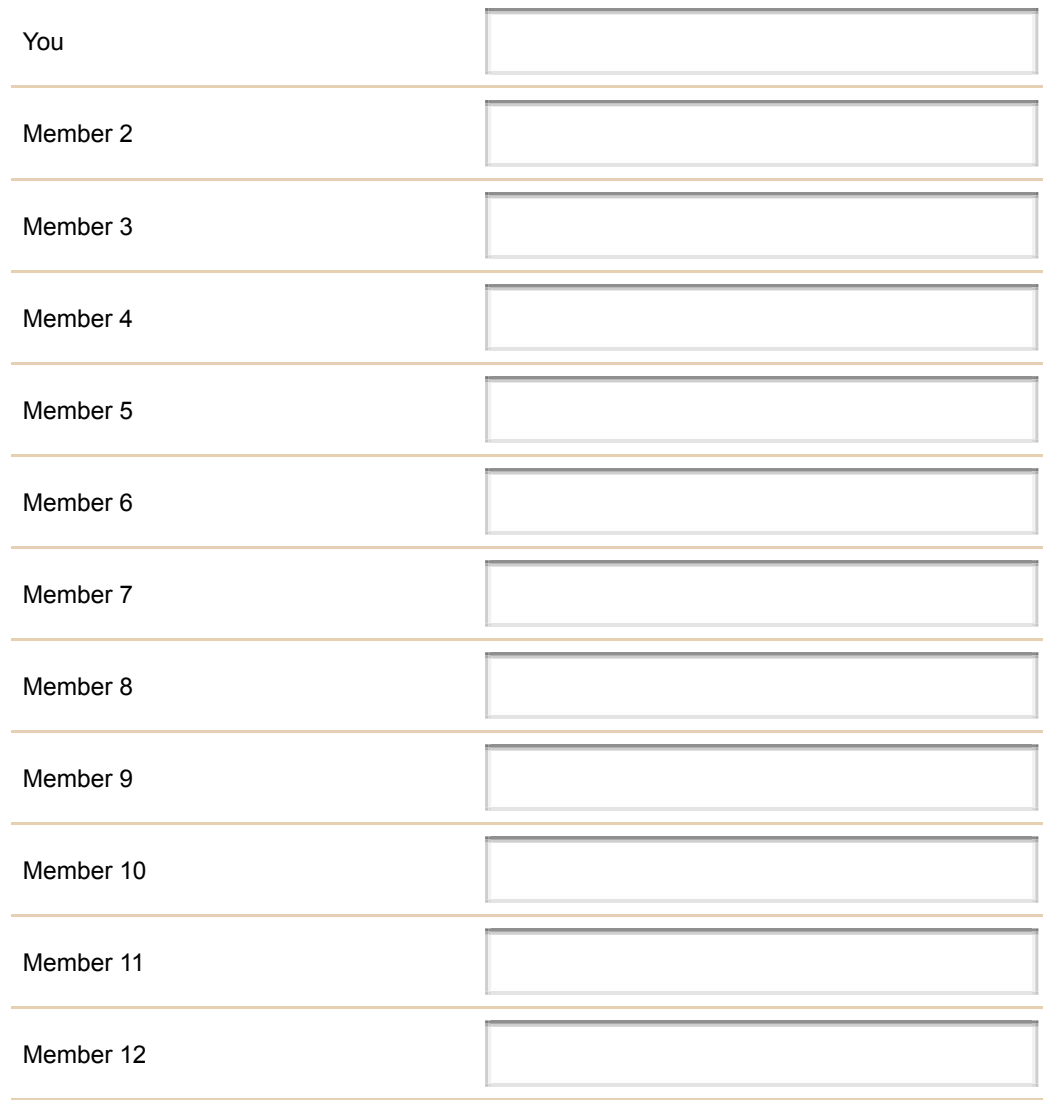


An email will be sent to you within the next week to confirm the time and place that you will meet for the discussion group.

Select here to end the survey

Thank You for your interest in our study but, you do not meet the qualifications that have been set. 


\section{APPENDIX E}

\section{Focus Group Questionnaire and Consent}




\section{Focus Group Questionnaire}

1. Name

2. Age

3. Gender: $\mathrm{M}$ F

4. School

5. Year in School

6. Major

7. Phone number

(So that we can contact you for the pilot test of the survey)

8. How long total have you been in any dinner group? number of months or ___ number of semesters, including this one

9. How often do you eat together?

10. Where do you eat?

$\square$ Same place each meal

$\square$ Rotate to each Participant's place

$\square$ Other: explain

11. Do you cook individually or with others when preparing meals?

12. How often do you personally cook?

13. How many people are currently in your dinner group?

14. How much does it usually cost you on a weekly basis?

15. What meals do you share?

$\square$ Breakfast

$\square$ Lunch

$\square$ Dinner

OVER $\rightarrow$ 
16. How many people are in your apartment? (roommates, including you)

17. How many of the people in your apartment are in the same dinner group? (including you)

18. Are you employed?

$\square$ No

$\square$ Yes $\rightarrow$ If Yes, where and how many hours a week do you work?

19. How many credits are you currently taking in school? 


\section{Dinner Group \\ Consent to be a Research Subject}

\section{Introduction}

This research study is being conducted by Associate Professor Lora Beth Brown, EdD, RD and Brita Ball, a graduate student, at Brigham Young University to determine how dinner groups are being conducted among college students.

\section{Procedures}

You have been invited to participate in a discussion group where you will be asked to share your experience with being in a dinner group. Before the discussion begins you will complete a questionnaire with 19 questions that will take about 5 minutes, about demographics and your dinner group. The discussion group will then follow and will last for about 60 minutes with more detailed discussion of participants' dinner groups. The discussion will be audio tape-recorded and then transcribed. Later you will be asked to pilot test a survey, with about 30 questions that will take less than 15 minutes to complete.

\section{Risks and Benefits}

There are no known risks associated with participation in this study. There are no direct benefits to subjects. However, it is hoped that through your participation researchers will learn more about dinner group practices.

\section{Confidentiality}

All information provided will remain confidential and will only be reported as group data with no identifying information. All data, including questionnaires and tapes/transcriptions from the focus group, will be kept in a locked storage cabinet and only those directly involved with the research will have access to them. After the research is completed, the questionnaires and tapes will be destroyed.

\section{Compensation}

Participants will receive ten dollars cash for participation in the discussion group.

\section{Participation}

Participation in this research study is voluntary. You have the right to withdraw at any time and it will not affect any present or future relations with Brigham Young University.

\section{Questions about the Research}

If you have questions regarding this study, you may contact Dr. Lora Beth Brown, EdD, RD, at (801) 422-6672, Lorabeth_Brown@byu.edu from the Department of Nutrition, Dietetics \& Food Science at Brigham Young University, S-245 ESC Provo, UT 84602

\section{Questions about your Rights as Research Participants}

If you have questions regarding your rights as a research participant, you may contact Christopher Dromey, PhD, Chair of the Institutional Review Board for Human Subjects, (801) 422-6461, 133 TLRB, Brigham Young University, Provo, UT 84602, Christopher_Dromey@byu.edu.

I have read, understood, and received a copy of the above consent and desire of my own free will to participate in this study. Date: 


\section{APPENDIX F}

\section{Focus Group Moderator's Guide}




\section{Focus Group Moderator's Guide about Dinner Groups}

\section{Purpose}

The purpose of this is to discover how people are conducting dinner groups, perceived benefits and barriers and how dinner groups are being conducted.

\section{Welcome}

I would first like to thank everyone for coming. My name is Brita. I will be the moderator for this discussion group. We are here to talk about participation in dinner groups. The information you share is to help me understand student dinner groups. My role as the moderator is to help us stay on topic and to make sure that all the important topics are covered.

Before we begin I would like to make you all aware of the fact that we will be audio recording the discussion. This allows me to be active in participation without having to take notes. It is also to make sure we get all the information as you say it. All of your comments will be confidential and no names will be link to specific statements.

Because of the recording it is important that we only have one person speaking at a time. Please take turns and try not to talk over each other. When listening to the tape it is hard to identify what is being said when multiple conversations are going on at once.

With that said we do want to hear from everyone. We are interested in everyone's opinions and personal experience with this topic. There are no right or wrong answers and you do not have to agree with each other.

\section{Ice Breaker}

Let's go around the room and have each person start by saying your name and what is your favorite restaurant and when do you usually eat there or who do you usually go there with?

\section{Introductory Questions}

To begin our discussion I would like to hear about the experience college students have with moving away from home and cooking their own meals.

Tell me about how dinner groups are started.

Who are the initiators?

\section{Practices}

Tell me about the ideal size of a dinner What makes that ideal?

What would you recommend to someone trying to organize a dinner group? What kind of assignments or reminders?

How do you handle dishes?

Tell me about the time commitment when it's your turn to cook.

What about when you aren't cooking?

Tell me about your experience with cooking for a dinner group. 
What kind of procedure do you have for when people miss dinner?

Tell me about the types of food that are made for your dinner group?

Tell me about rules that have been set for meals: formal or unspoken.

Tell me about the change in your eating habits since joining a dinner group.

What about outside of the dinner group?

What are your experiences with people dropping out?

What are reasons people give for dropping out?

\section{Benefits}

Tell me about the reasons students decide to join a dinner group.

What kind of social benefits are there?

Tell me about the change in cost for food?

What kind of skills did you learn through participation in a dinner group?

What are benefits of actually cooking?

Tell me about your level of confidence in cooking before and after joining your dinner group.

\section{Difficulties}

In your opinion, what are any negative aspects to participating in a dinner group?

Tell me about any negative aspects related to time.

Tell me about problems encountered with food taste.

What about pressure of preparing a meal?

What are your experiences with people having different expectations?

Tell me about reasons students don’t join?

\section{Conclusion}

If you were trying to convince someone to join a dinner group, what would you say?

Was there anything else that you learned from participating in a dinner group that we have not covered?

How do you think your experience in a dinner group will affect you after you leave BYU? What sort of carryover into your life after being a student?

Would you join again?

What makes you say that? 
APPENDIX G

Focus Group Themes 


\section{Tree Nodes}

- Benefits

o Convenience

o Fridge

o Future

o Healthy

o Money

o Saving Time

o Social

- Food

o Cooking

o Cooking for One

o Exposure

o Old and New

o Other Eating

o Picky

o Quality

o Recipes

o Variety

- Framework

o Attendance

o Big

o Dishes

o Doggie Bag

o Drop Out

o Group Stability

o Guests

o Organize

- Roommates

- Ward

o Standards

o Time Spent

- Guys

- Negative

o Time Negative

- Positive 
APPENDIX $\mathrm{H}$

Survey 


\section{Dinner Group Survey}

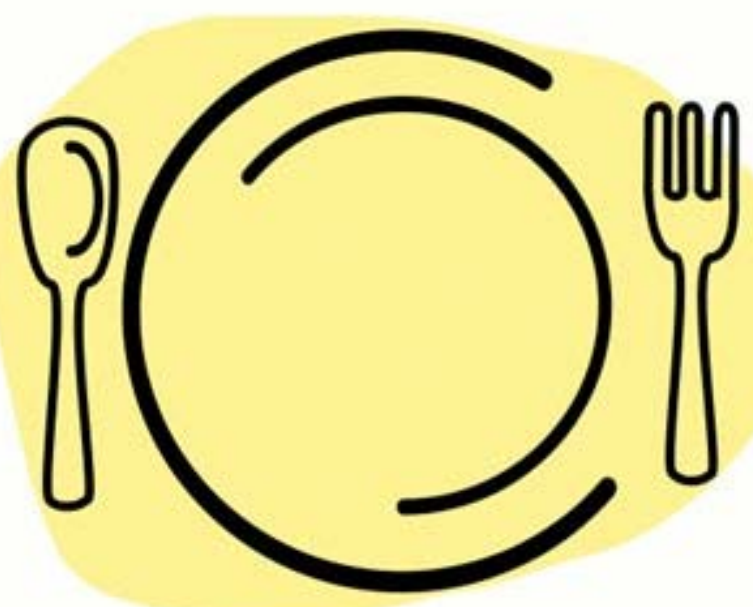

Conducted by Brita Ball

Dept of Nutrition, Dietetics and Food Science

Brigham Young University 
This survey is being conducted by Brita Ball to determine how college students are conducting dinner group, and their perceptions of benefits and difficulties of participation.

Participants will be chosen from those in the discussion groups and their dinner group members.

The survey consists of 71 questions and will take 5 to 10 minutes to answer.

There are no known risks for participation in this study.

The benefits of participating are discovering the benefits college students receive from participation in dinner groups and future promotion of more widespread participation in dinner groups.

Involvement in this research project is voluntary. You may withdraw at any time without penalty or refuse to participate entirely. There will be no reference to your identification at any point in the research.

If you have questions regarding this study you may contact Dr. Brown at (801) 422-6672. If you have questions regarding your rights as a participant in research projects, you may contact:

IRB Administrator,

A-285 ASB Campus Drive, Brigham Young University

Provo, UT 84602

Phone: (801) 422-1461

Email: irb@byu.edu. 
For the following statements select the level of agreement or disagreement that best represents how you feel about each statement.

\begin{tabular}{|c|c|c|c|c|c|}
\hline Reasons for Joining & & & & & \\
\hline $\begin{array}{l}\text { 1. Saving time was a reason I had for joining a dinner } \\
\text { group. }\end{array}$ & SA & A & $\mathbf{U}$ & D & SD \\
\hline $\begin{array}{l}\text { 2. Saving money was a reason I had for joining a dinner } \\
\text { group. }\end{array}$ & SA & $\mathbf{A}$ & $\mathbf{U}$ & D & SD \\
\hline $\begin{array}{l}\text { 3. Eating healthier was a reason I had for joining a dinner } \\
\text { group. }\end{array}$ & SA & $\mathbf{A}$ & $\mathbf{U}$ & D & SD \\
\hline $\begin{array}{l}\text { 4. Eating a better variety of foods was a reason I had for } \\
\text { joining a dinner group. }\end{array}$ & SA & $\mathbf{A}$ & $\mathbf{U}$ & D & SD \\
\hline $\begin{array}{l}\text { 5. Social interaction was a reason I had for joining a } \\
\text { dinner group. }\end{array}$ & SA & $\mathbf{A}$ & $\mathbf{U}$ & $\mathbf{D}$ & SD \\
\hline
\end{tabular}

Eating Dinner or Main Meal Alone

\begin{tabular}{|c|c|c|c|c|c|}
\hline $\begin{array}{l}\text { 6. When I eat alone I make large portions of one thing and } \\
\text { eat the leftovers until it is gone. }\end{array}$ & SA & A & $\mathbf{U}$ & $\mathbf{D}$ & SD \\
\hline $\begin{array}{l}\text { 7. When I eat alone I don't feel I have enough money to } \\
\text { make dinner every night. }\end{array}$ & SA & A & $\mathbf{U}$ & $\mathbf{D}$ & SD \\
\hline $\begin{array}{l}\text { 8. When I eat alone I eat a lot of the same things over and } \\
\text { over. }\end{array}$ & SA & A & $\mathbf{U}$ & $\mathbf{D}$ & SD \\
\hline $\begin{array}{l}\text { 9. When I eat alone it is hard to think of something to } \\
\text { eat every day. }\end{array}$ & SA & A & $\mathbf{U}$ & $\mathbf{D}$ & SD \\
\hline 10. When I eat alone I eat a lot of convenience foods. & SA & $\mathbf{A}$ & $\mathbf{U}$ & $\mathbf{D}$ & SD \\
\hline 11. When I eat alone I eat on campus a lot. & SA & A & $\mathbf{U}$ & $\mathbf{D}$ & SD \\
\hline 12. When I eat alone I don't eat very healthy. & SA & A & $\mathbf{U}$ & D & SD \\
\hline
\end{tabular}


Eating Habits and Skills

13. How I eat outside of my dinner group has not

changed since being in a dinner group.

14. My food habits outside of my dinner group have improved since joining the dinner group.

15. My confidence in my cooking has increased since joining a dinner group.

16. My cooking skills have increased since I joined a dinner group.

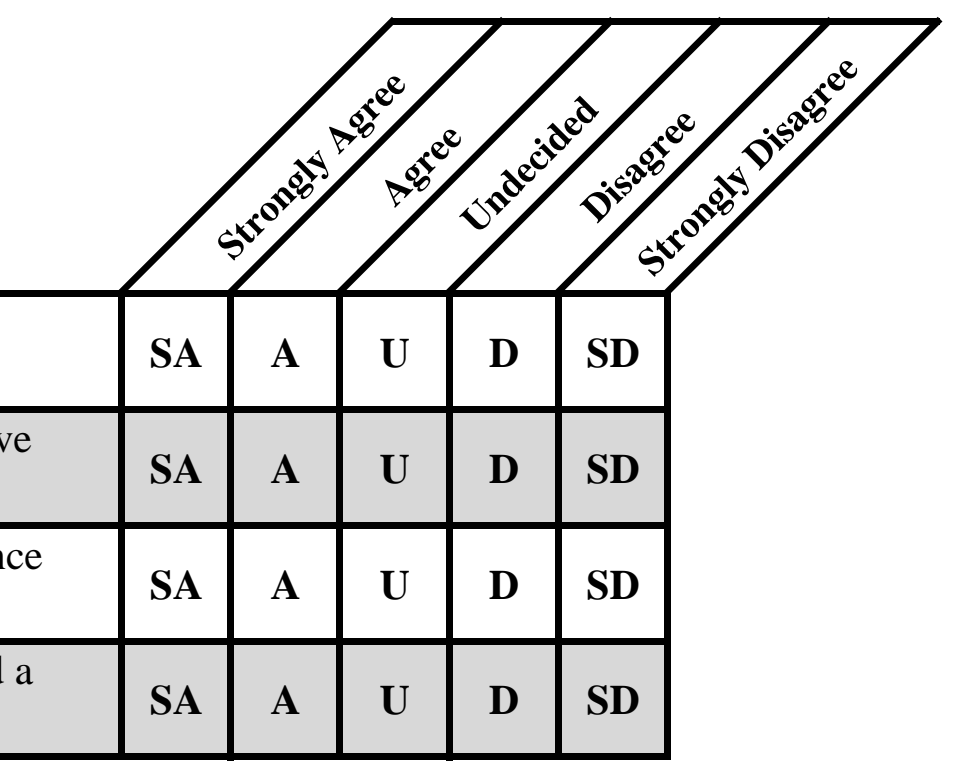

Time Factors

17. Socializing at my dinner group can take more time than I would normally spend on dinner.

18. I save time on the days I don't cook by attending my dinner group.

19. Before joining a dinner group time was a barrier to joining.

20. Time is a barrier to participation in my dinner group.

21. Overall the time spent was worth the benefits of attending my dinner group.

22. Participating in a dinner group takes time away from work or school.

23. I get better food for the amount of time spent on dinner.

SA
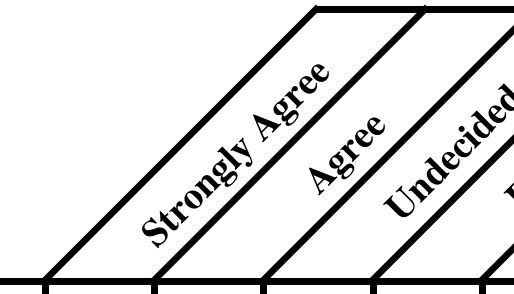

(2)

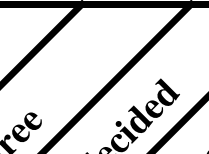

SA

\begin{tabular}{|l|l|l|l}
\hline$A$ & U & D & SD \\
\hline
\end{tabular}

SA

SA

A

U

D

SD

SA

A

$\mathbf{U}$

D SD

-




\section{Social Experiences}

24. The social aspect is my favorite part of my dinner group.

25. I enjoy the opportunity to just talk to people at my dinner group.

26. I joined a dinner group to meet new people.

27. I joined a dinner group to strengthen relationships.

28. Being in a dinner group is fun.

29. My dinner group is a break from school and work.

30. I wanted to join a dinner group because I missed eating family meals.

31. Being in a dinner group creates the feel of being in a family.

\begin{tabular}{|c|c|c|c|c|}
\hline SA & $\mathbf{A}$ & $\mathbf{U}$ & D & SD \\
\hline SA & $\mathbf{A}$ & $\mathbf{U}$ & D & SD \\
\hline SA & $\mathbf{A}$ & $\mathbf{U}$ & D & SD \\
\hline SA & $\mathbf{A}$ & $\mathbf{U}$ & D & SD \\
\hline SA & A & $\mathbf{U}$ & D & SD \\
\hline SA & $\mathbf{A}$ & $\overline{\mathbf{U}}$ & D & SD \\
\hline SA & A & $\mathbf{U}$ & D & SD \\
\hline SA & A & $\mathbf{U}$ & D & SD \\
\hline
\end{tabular}

Health and Money

\begin{tabular}{|l|c|c|c|c|c|}
\hline 32. I equate variety in foods with healthier eating. & SA & A & U & D & SD \\
\hline 33. Less processed foods are healthier foods. & SA & A & U & D & SD \\
\hline 34. Homemade foods are generally healthy. & SA & A & U & D & SD \\
\hline 35. Healthy foods are expected in our dinner group. & SA & A & U & D & SD \\
\hline $\begin{array}{l}\text { 36. Eating in a dinner group makes healthy eating } \\
\text { affordable. }\end{array}$ & SA & A & U & D & SD \\
\hline 37. I save money being in a dinner group. & SA & A & U & D & SD \\
\hline 38. I learned about meal costs being in a dinner group. & SA & A & U & D & SD \\
\hline
\end{tabular}




\section{Challenges}

39. The food that we eat in dinner group is not food that I would choose to eat on my own.

40. I feel that relying on other people in a dinner group is hard.

41. I am unsure if the benefits of a dinner group are real.

42. Having other things to get done on the same day that I cook is stressful.

43. I feel stress when deciding what to cook.

44. I feel stressed about getting food done on time.

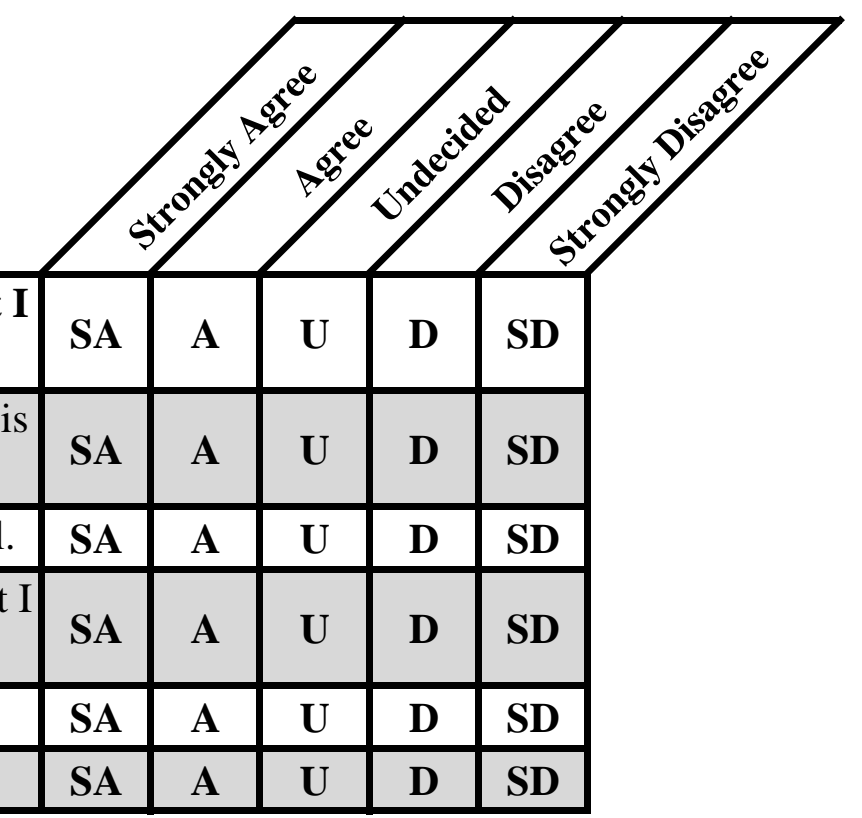

Indicate the frequency of each statement.

Other People

45. I feel like our dinner group is a competition and/or there is pressure to be the best cook.

46. I feel intimidated by other people's cooking.

47. I worry about people liking the food I prepare.

48. People forget it's their night.

49. People don't uphold the food standards.

50. People don't help clean up.

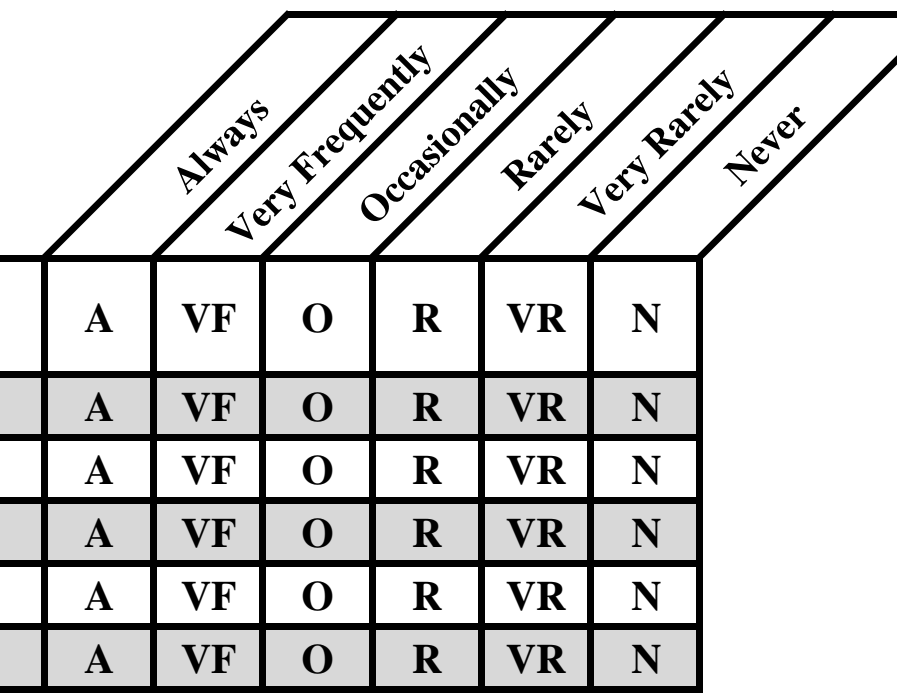

Overall Experience in a Dinner Group

\begin{tabular}{|c|c|c|c|c|c|}
\hline $\begin{array}{l}\text { 51. I feel the social interaction is a benefit of being in a } \\
\text { dinner group. }\end{array}$ & SA & A & $\mathbf{U}$ & $\mathbf{D}$ & SD \\
\hline 52. I feel I eat healthier food being in a dinner group. & SA & A & $\mathbf{U}$ & $\mathbf{D}$ & SD \\
\hline $\begin{array}{l}\text { 53. I feel that I get more variety of food in my dinner } \\
\text { group. }\end{array}$ & SA & $\mathbf{A}$ & $\mathbf{U}$ & $\mathbf{D}$ & SD \\
\hline 54. I save money being in a dinner group. & SA & $\mathbf{A}$ & $\mathbf{U}$ & $\mathbf{D}$ & SD \\
\hline 55. I save time being in a dinner group. & SA & $\mathbf{A}$ & $\mathbf{U}$ & $\mathbf{D}$ & SD \\
\hline
\end{tabular}


Dinner Group Basics: Please select the best answer choice for each question.

56. How many people are in your current (or most recent) dinner group?
3-4
5-6
$7-8$
$9-10$
11-12
$\square \quad>12$

57. Who is in your dinner group?

$\square$ Only Roommates

$\square \quad$ Roommates and others

$\square \quad$ Only people outside my apartment

58. Do you cook individually or collectively?

$\square \quad$ Individually

$\square \quad$ Individually, but people help if they can

$\square$ Collectively

59. How often do you eat together?

$\square \quad 4$ days a week

5 days a week

6 days a week

- 7 days a week

60 . How often is someone in the group absent?

$\square \quad$ Every other week

口 Once a week

$\square \quad$ Every other day

$\square$ Every day

61. On a given day how many people are absent?
$\square \quad 0$
1-2
3-4
$\square>4$ 
62. How much time do you spend preparing, eating and cleaning up on days you cook?
$\square \quad$ Between 0 and 2 hours
- Between 2 and 4 hours
Between 4 and 6 hours
口 More than 6 hours

63. How much time do you spend eating, helping and socializing on days you DONT cook?
- Between 0 and 30 minutes
․ Between 30 and 60 minutes
Between 60 and 90 minutes
$\square \quad$ Over 90 minutes

64. In total, how long have you been in any dinner group?

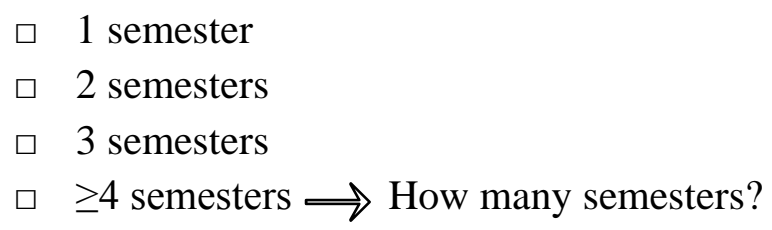

Demographics: Please select the best answer choice for each question.

65. What is your gender?
$\square \quad$ Male
口 Female

66. Are you now attending or enrolled in school?

Yes, full time student

$\square$ Yes, part time student

$\square \quad$ No, not a current student $\Longrightarrow$ If no skip to question 69 , next page

67. What year in school are you?

Freshman

$\square$ Sophomore

$\square$ Junior

$\square$ Senior

口 Graduate Student 
68. What is your major?

69. Are you currently employed?

$\square \quad$ Yes

$\square \quad$ No $\Longrightarrow$ If no, skip to question 71

70. How many hours did you work last week?
0
$\square \quad 1-5$
6-10
11-15
ㅁ 16-20
ㅁ 21-25
$\square \quad 26-30$
ㅁ $>30$

71. What is your age as of January 1, 2010?

Thank you for taking the time to complete our survey!

Please return the survey to ESC, S-221 